\title{
Apoptotic human cells inhibit migration of granulocytes via release of lactoferrin
}

\author{
Irini Bournazou,, John D. Pound, ${ }^{1}$ Rodger Duffin, ${ }^{1}$ Stylianos Bournazos, ${ }^{1}$ Lynsey A. Melville, ${ }^{1}$ \\ Simon B. Brown, ${ }^{1}$ Adriano G. Rossi, ${ }^{1}$ and Christopher D. Gregory ${ }^{1,2}$
}

1The University of Edinburgh/Medical Research Council (MRC) Centre for Inflammation Research, Queen's Medical Research Institute, Edinburgh, United Kingdom. ${ }^{2}$ ImmunoSolv Ltd., Edinburgh, United Kingdom.

\begin{abstract}
Apoptosis is a noninflammatory, programmed form of cell death. One mechanism underlying the non-phlogistic nature of the apoptosis program is the swift phagocytosis of the dying cells. How apoptotic cells attract mononuclear phagocytes and not granulocytes, the professional phagocytes that accumulate at sites of inflammation, has not been determined. Here, we show that apoptotic human cell lines of diverse lineages synthesize and secrete lactoferrin, a pleiotropic glycoprotein with known antiinflammatory properties. We further demonstrated that lactoferrin selectively inhibited migration of granulocytes but not mononuclear phagocytes, both in vitro and in vivo. Finally, we were able to attribute this antiinflammatory function of lactoferrin to its effects on granulocyte signaling pathways that regulate cell adhesion and motility. Together, our results identify lactoferrin as an antiinflammatory component of the apoptosis milieu and define what we believe to be a novel antiinflammatory property of lactoferrin: the ability to function as a negative regulator of granulocyte migration.
\end{abstract}

\section{Introduction}

Apoptosis is a programmed, physiological form of cell death that, in inflammatory terms, is quiet: apoptotic cells are rapidly phagocytosed by their neighbors or by mononuclear phagocytes that are attracted by chemotactic factors such as lysophosphatidylcholine (1) and fractalkine (2) released by apoptotic cells. The rapid engulfment of apoptotic cells militates against the potential tissue-injuring and proinflammatory features of dead cells as exemplified by necrosis (3-6). Indeed, failed or delayed clearance of apoptotic cells can have detrimental inflammatory consequences, including the development of autoimmune pathologies (7-9). The mechanisms underlying the non- or antiinflammatory nature of the apoptosis program are not understood in detail. Antiinflammatory mediators such as TGF- $\beta 1$ and IL- 10 are known to be produced at sites of apoptosis, both directly by apoptotic cells themselves and indirectly through interaction of apoptotic cells with phagocytes (10, 11). Apoptotic cells selectively attract mononuclear phagocytes $(1,12)$, but, curiously, the other class of professional phagocytes, granulocytes or polymorphonuclear phagocytes, do not migrate toward apoptotic cells in vitro (12) and do not normally engage in apoptotic cell engulfment. The absence of granulocytes from sites of homeostatic and developmental apoptosis suggests that apoptotic cells have the potential to selectively regulate the recruitment of mononuclear leukocytes.

In marked contrast to sites of apoptosis, sites of acute infection are characterized by the presence of granulocytes, most commonly neutrophils, as a means to protect the host by engulfing, killing, and digesting invading infectious agents. Neutrophils, as a first line of immune defense, are rapidly recruited to the site of infection in response to a variety of inflammatory stimuli, including

Conflict of interest: C.D. Gregory and J.D. Pound are founders of the company, ImmunoSolv Ltd., that supplied 2 of the monoclonal anti-lactoferrin antibodies used in Supplemental Figure 1.

Nonstandard abbreviations used: BL, Burkitt lymphoma; $\left[\mathrm{Ca}^{2+}\right]_{\mathrm{i}}$, intracellular calcium concentration; $\mathrm{fMLP}$, formyl-methionyl-leucyl-phenylalanine; $\mathrm{LTB}_{4}$, leukotriene $\mathrm{B}_{4}$. Citation for this article: J. Clin. Invest. 119:20-32 (2009). doi:10.1172/JCI36226. chemokines, cytokines, leukotrienes, and bacterial components such as LPS and $N$-formylated peptides $(13,14)$. Comparative studies on the slime mold Dictyostelium discoideum have shown that in response to chemoattractants, neutrophils orient themselves and migrate in an "ameboid motion" by anterior pseudopod extension accompanied by simultaneous posterior contraction and retraction. Such polarized morphology is characterized by the formation of a lamellipodium at the leading edge and a uropod at the trailing edge of the neutrophil (15-18). This process is tightly controlled not only to ensure the efficient migration of neutrophils to inflammatory sites, but also to prevent their aberrant infiltration and consequent tissue-damaging activities. Detrimental effects of neutrophils - caused, for example, by release of their proteolytic enzymes - contribute to many pathological inflammatory conditions, ranging from vasculitis and ischemia/reperfusion injury to glomerulonephritis, rheumatoid arthritis, and acute graft rejection (19). Therefore, at inflammatory sites, negative signals exist that prevent neutrophil recruitment, dampen neutrophil responsiveness, and counterbalance or terminate the inflammatory response. This antiinflammatory program is characterized by cessation of neutrophil infiltration, as arachidonic acid-derived prostaglandins and leukotrienes are switched to lipoxins, resolvins, and protectins $(20,21)$. Resolution of inflammation is ultimately achieved through neutrophil apoptosis, and apoptotic neutrophils are subsequently phagocytosed by macrophages, a process that leads to the release not only of antiinflammatory cytokines but also of such antiinflammatory and proresolving lipid mediators as lipoxin A4, resolvin E1, and protectin D1 (22-25).

Given (a) the production of negative signaling molecules at inflammatory sites to limit neutrophil recruitment and function and (b) failure of neutrophil migration to sites of apoptosis, we sought to determine whether apoptotic cells actively produce negative regulators of neutrophil chemotaxis. We postulated that the production by apoptotic cells of factors that inhibit neutrophil migration contribute to the non-phlogistic nature of the apoptosis program. Here, we present evidence that apoptotic cells actively inhibit neutrophil migration through the production of 
A

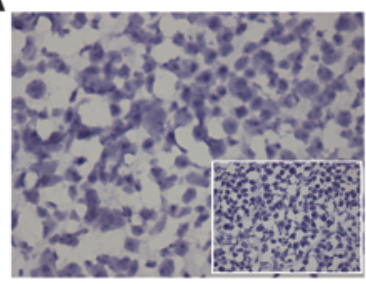

C

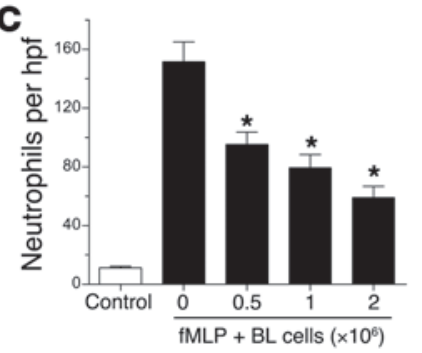

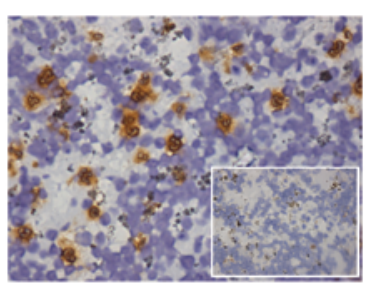

B
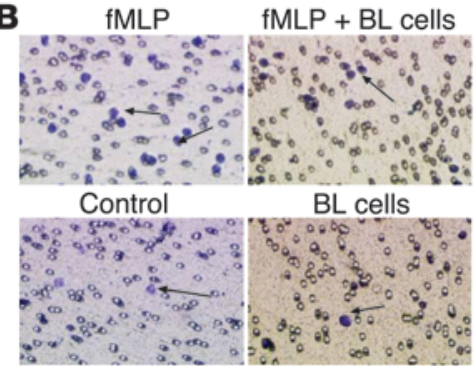

D

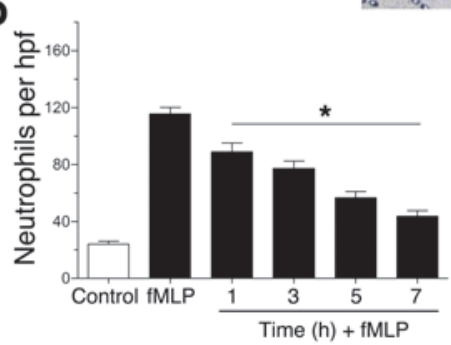

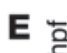

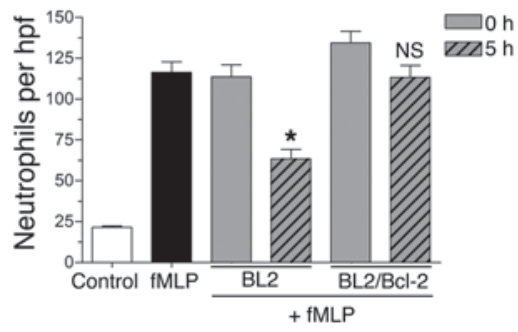

Figure 1

Apoptotic cells release factor(s) that inhibit neutrophil migration. (A) Immunohistochemical analysis of neutrophils in BL (left) and spleen (positive control; right) sections. Inset images represent isotype control. (B) Representative images of stained Transwell filters. (C) Neutrophil chemotaxis toward increasing concentrations of BL cells was assessed in the presence of fMLP $(100 \mathrm{nM}) . n=3 ;{ }^{*} P<0.05 \mathrm{vs}$. time 0 . (D) BL cell-conditioned media obtained at the indicated time points were used to analyze fMLP-induced neutrophil chemotaxis. $n=3 ;{ }^{*} P<0.05$ vs. fMLP. (E) Neutrophil chemotaxis toward fMLP was analyzed in the presence of control or Bcl-2-transfected BL2 cells obtained following a 0- and 5-hour incubation at $37^{\circ} \mathrm{C} . n=3 ;{ }^{*} P<0.05$ vs. BL2 $0 \mathrm{~h}$; NS vs. BL2/Bcl-2 $0 \mathrm{~h}$. Apoptosis levels were assessed by flow cytometry following staining with annexin $\mathrm{V} /$ propidium iodide. Error bars indicate SEM. Original magnification; ×400 (A; A, insets; B). hpf, high-power field.

lactoferrin, an $80 \mathrm{kDa}$ antiinflammatory glycoprotein that specifically inhibits chemotaxis of neutrophils but not mononuclear phagocytes. Lactoferrin was found to be synthesized de novo following triggering of apoptosis and released by apoptotic cells of diverse lineages. Lactoferrin impaired neutrophil activation and prevented mobilization of the cells by inhibiting migratory polarization of the cell body. These results demonstrate that the non-phlogistic constitution of apoptotic cells includes an antiinflammatory molecule, lactoferrin, that we show, for the first time to our knowledge, has potent negative regulatory effects on neutrophil migration. These findings provide a rationale for the absence of neutrophils from apoptotic sites and have important implications for understanding the mechanisms involved in the resolution phase of inflammation.

\section{Results}

Apoptotic cells actively produce factor(s) that inhibit neutrophil chemotaxis. To address whether apoptotic cells influence migratory activity of neutrophils, we carried out a series of in vitro Boyden-type chemotaxis assays to investigate neutrophil migration toward Burkitt lymphoma (BL) cells. We initially employed BL as a model tissue as these tumor cell populations display high levels of apoptosis, a property that is retained constitutively in the tumor-derived cell lines. As at all sites of apoptosis, there is marked infiltration of macrophages that engulf the apoptotic cells, giving rise to the typical "starry sky" histological appearance of this tumor. As shown in Figure 1A (left), while macrophages were abundant in histological sections of BL, neutrophils were absent. We assessed the effects of BL cells on the migratory activity of neutrophils in vitro by adding neutrophils to the top compartment of a Transwell filter and inducing them to migrate toward the lower chamber containing $\mathrm{BL}$ cells in the presence of the powerful neutrophil chemoattractant formyl-methionyl-leucyl-phenylalanine (fMLP) (Figure 1B). As shown in Figure 1C, neutrophil migration was significantly inhibited in BL cells in a concentration-dependent manner. We observed a similar effect irrespective of the chemoattractant used (inhibition of neutrophil migration induced by C5a, IL-8, and leukotriene $\mathrm{B}_{4}$ $\left[\mathrm{LTB}_{4}\right]$; data not shown, but see below). We carried out subsequent chemotaxis assays using BL-conditioned medium obtained over a 7-hour time course and found that BL cells actively released an inhibitory factor(s) (Figure 1D). The release of the inhibitory factor appeared to be linked to the levels of apoptosis in the BL cell populations, since the inhibitory activity was significantly lower in further chemotaxis assays using BL-conditioned medium derived from cells overexpressing the apoptosis inhibitor Bcl-2, as compared with that of parental cells (Figure 1E).

Biochemical characterization of neutrophil migration-inbibitory factor(s). In an attempt to gain further insight into the biochemical nature of the factor(s) that BL cells secrete in order to exclude neutrophils from their environment, we initially estimated the molecular weight range of the inhibitory factor(s) by using filters with molecular weight cutoff points of approximately 3, 10, 30, 50 , and $100 \mathrm{kDa}$. BL-conditioned media obtained after 24-hour incubation were fractionated, and each fraction was examined in vitro using the neutrophil chemotaxis assay described above. The results revealed that fractions containing molecules of less than $50 \mathrm{kDa}$ failed to display any inhibitory effect on neutrophil migration (Figure 2A). However, the use of $100 \mathrm{kDa}$ filters revealed that both fractions ( $>100 \mathrm{kDa}$ and $<100 \mathrm{kDa}$ ) displayed an inhibitory effect on neutrophil migration, indicating that at least 1 factor has a molecular weight that ranges between 50 and $100 \mathrm{kDa}$. The presence of inhibitory activity in the filtrate of the $100 \mathrm{kDa}$ 

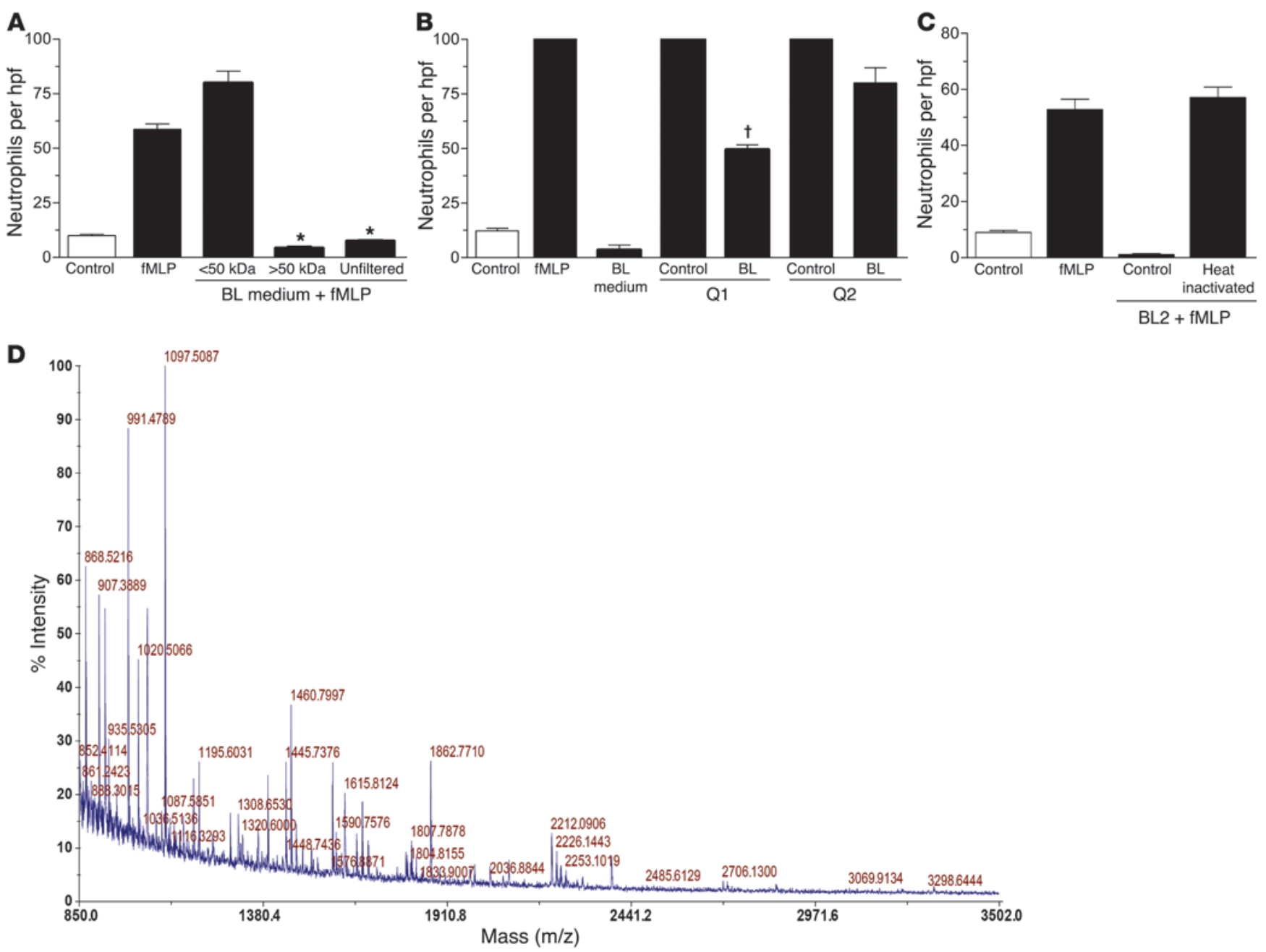

Figure 2

Biochemical characterization of the inhibitory factor. Conditioned media from BL2 cells cultured for 24 hours were size fractionated using filters with $50 \mathrm{kDa}$ (A) molecular weight cutoff sizes. Unfiltered medium was included as control. ${ }^{*} P<0.001$ compared with the corresponding positive control. Error bars indicate SEM. Ion exchange analysis included the use of Q Sepharose beads (positively charged) in order to distinguish positively and negatively charged molecules in the $<100 \mathrm{kDa}$ fraction (B) of the BL medium. Unbound molecules (Q1 fraction) were collected, whereas bound molecules were eluted from the beads (Q2 fraction). Neutrophil migration toward these fractions in the presence of $\mathrm{fMLP}$ (100 $\mathrm{nM}$ ) was assessed. Q1 and Q2 fractions (unbound and eluant fraction) of serum-free medium (no $\mathrm{BL}$ ) were included as control. ${ }^{\dagger} P<0.05$ compared with the corresponding control. Error bars indicate SEM. (C) Chemotaxis assay of neutrophils toward BL-conditioned medium that was heat inactivated $\left(90^{\circ} \mathrm{C}\right.$ for 10 minutes). (D) MALDI-TOF mass spectrum for the tryptic digest of the peptide band identified as lactoferrin.

cutoff membrane is likely to result from (a) imprecise molecular weight cutoff of molecules in the $50-100 \mathrm{kDa}$ range, (b) complex formation through multimerization of the $50-100 \mathrm{kDa}$ factor or through interaction with other molecules, or (c) the existence of a distinct inhibitory activity of greater than $100 \mathrm{kDa}$. It should be noted that the selected isolation approach is skewed in favor of proteins and that additional low-molecular-weight (for example, lipid) mediators of neutrophil migration inhibition would not be identified by these procedures.

To investigate further the biochemical properties of the retentate and filtrate of the $100 \mathrm{kDa}$ cutoff membrane, we first determined the charge ( $\mathrm{pI}$ value) of the migration-inhibitory activity by means of an ion exchange analysis of BL-conditioned media. Using positively charged ion exchange beads (Q Sepharose), the $100 \mathrm{kDa}$ membrane retentate and filtrate were separated into posi- tively charged (Q-supernatant) and negatively charged (Q-eluant) fractions. As shown in Figure 2B, the filtrate of the $100 \mathrm{kDa}$ membrane ( $<100 \mathrm{kDa}$ fraction) contained migration-inhibitory activity in both the supernatant (positive charge) and the eluant (negative charge) of the $\mathrm{Q}$ beads. By contrast, analyses of the retentate (>100 kDa fraction) revealed that only the negatively charged eluant displayed significant activity in inhibiting neutrophil migration. These results indicate that at least 2 moieties with neutrophil migration-inhibitory activity were present in BL cell-conditioned medium: one of 50-100 kDa with positive $\mathrm{pI}$ and a second of $100 \mathrm{kDa}$ or more and negatively charged.

We subsequently determined whether the neutrophil migrationinhibitory activity was heat labile. As shown in Figure 2C, heat inactivation completely abrogated all chemotaxis inhibitory activity in BL cell-conditioned medium, suggesting that the inhibitory 

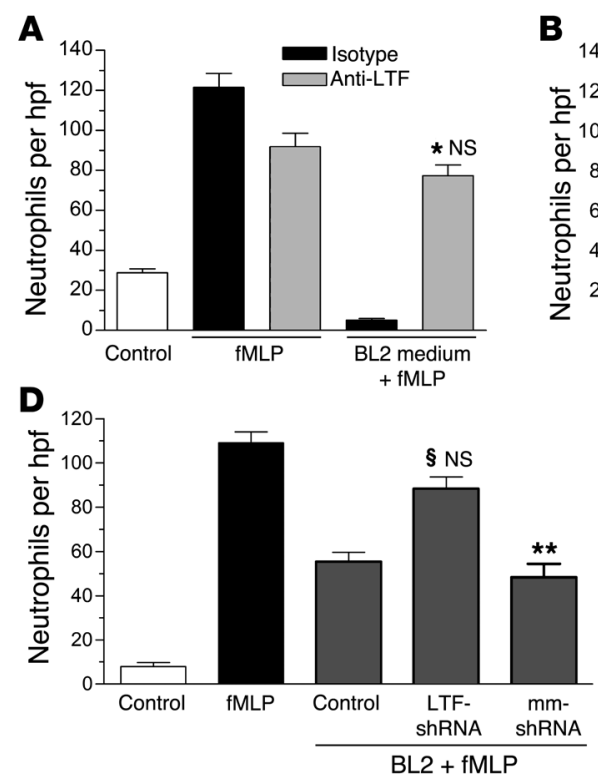

B

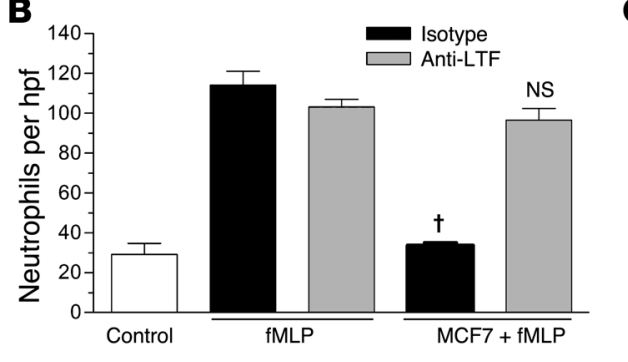

$\mathbf{E}$

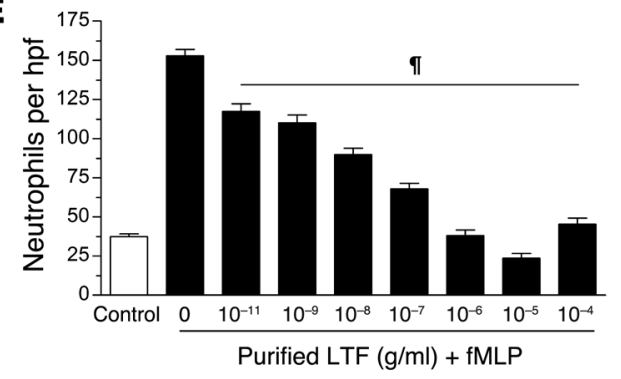

Figure 3

Lactoferrin specifically inhibits neutrophil chemotaxis. Neutrophil chemotaxis in the presence of human anti-lactoferrin (anti-LTF) polyclonal antibody (gray) or isotype control (black) using conditioned media from BL (A) and MCF7 (B) cells (A: $n=3,{ }^{\star} P<0.05$ vs. isotype control, NS vs. fMLP anti-lactoferrin control; $\mathbf{B} ; n=3,{ }^{\dagger} P<0.001$ vs. fMLP/isotype; NS vs. fMLP/anti-LTF. (C) RT-PCR analysis to assess lactoferrin expression in BL cells stably expressing LTF shRNA (LTF) cells and mock-transfected $(\mathrm{mm})$ cells induced to become apoptotic $\left(1 \mu \mathrm{M}\right.$ staurosporine; $\left.37^{\circ} \mathrm{C}\right)$. (D) Chemotaxis assay to determine neutrophil migration toward supernatants obtained from control, LTF shRNA, and mock-transfected BL cells $\left(n=5 ; § P<0.05\right.$ compared with mm shRNA control; ${ }^{* \star} P<0.05$ compared with fMLP; NS compared with fMLP control). (E) Dose-response analysis of purified human lactoferrin. $n=3$; $\uparrow P<0.05 \mathrm{vs} .0 \mathrm{~g} / \mathrm{ml}$ purified LTF + fMLP. Error bars indicate SEM.

factor(s) were most likely protein in nature. We then analyzed the proteins released from BL cells in viable and apoptotic states by protein fingerprinting. Polypeptide bands of greater than $50 \mathrm{kDa}$ were excised from a 10\% SDS polyacrylamide gel. Tryptic peptides were gel extracted, and matrix-assisted laser desorption/ionization-time of flight (MALDI-TOF) mass spectrometric analysis was carried out (Figure 2D). Also, given the crude biochemical characteristics described above, we undertook a candidate approach based on the proteins released from apoptotic BL cells. We identified the factor released by BL cells that prevented neutrophil chemotaxis as lactoferrin.

Lactoferrin specifically inhibits neutrophil chemotaxis toward a range of chemoattractants. Lactoferrin is a glycoprotein of approximately $75-80 \mathrm{kDa}$ that belongs to the transferrin family of proteins due to its iron-binding properties. It is a well-characterized component of neutrophil secondary granules, lacrimal fluid, colostrum, saliva, and mucosal secretions, in which it confers antibacterial activity. We observed that addition of anti-lactoferrin antibody to BL-conditioned medium neutralized its neutrophil migration-inhibitory activity using either polyclonal or monoclonal antibodies (Figure 3A and Supplemental Figure 1; supplemental material available online with this article; doi:10.1172/JCI36226DS1). Similar results were observed with supernatants obtained from the mammary carcinoma line MCF-7, indicating that the neutrophil migration-inhibitory activity is not restricted to BL cell-derived lactoferrin (Figure 3B). Furthermore, lactoferrin purified from human milk displayed dose-dependent inhibitory activity toward neutrophil migration in response to fMLP (Figure 3E) and also inhibited migration toward C5a, IL-8, and $\mathrm{LTB}_{4}$ to similar levels (Figure 4A). The neutrophil migration-inhibitory effect was also displayed by lactoferrin purified from human neutrophils (Figure 4D). It should be noted that both types of purified lactoferrin used in this study were free of endotoxin contamination, and the observed inhibitory effect did not appear to be due to any lactoferrin-associated molecules such as LPS. Furthermore, inhibition of lactoferrin expression by shRNA in BL cells provides additional support for the specificity of the observed lactoferrin effect. Thus, we found that neutrophil chemotaxis toward supernatants obtained from BL2 cells transfected with shRNA vectors targeted against lactoferrin was higher compared with supernatants from BL control or mock-transfected cells (Figures 3, C and D). Lactoferrin exerted no toxic effects on neutrophils, as assessed by annexin $\mathrm{V} /$ propidium iodide staining of control and lactoferrintreated neutrophils (>98\% cell viability). These results suggested that lactoferrin binds to neutrophils and inhibits their ability to undergo chemotaxis. To exclude the possibility that the observed inhibitory activity of lactoferrin was due instead to its ability to bind and functionally neutralize the chemoattractants, additional chemotaxis assays were performed using chemoattractants (fMLP, C5a, IL-8) that were preabsorbed with lactoferrin. To achieve this, we preincubated chemoattractants with lactoferrin. Subsequently, anti-lactoferrin antibody was used to remove the lactoferrin with the aid of magnetic beads. As shown in Figure 4B, no difference in neutrophil chemotactic activity was observed between the control and lactoferrin-absorbed chemoattractants, which excludes the possibility that lactoferrin binds to, and alters the activity of, the chemoattractants. Further supporting our conclusion that lactoferrin exerts its inhibitory effects through binding to neutrophils, we also observed that purified lactoferrin can directly associate with neutrophils (Figure 4C). In addition, Scatchard binding 

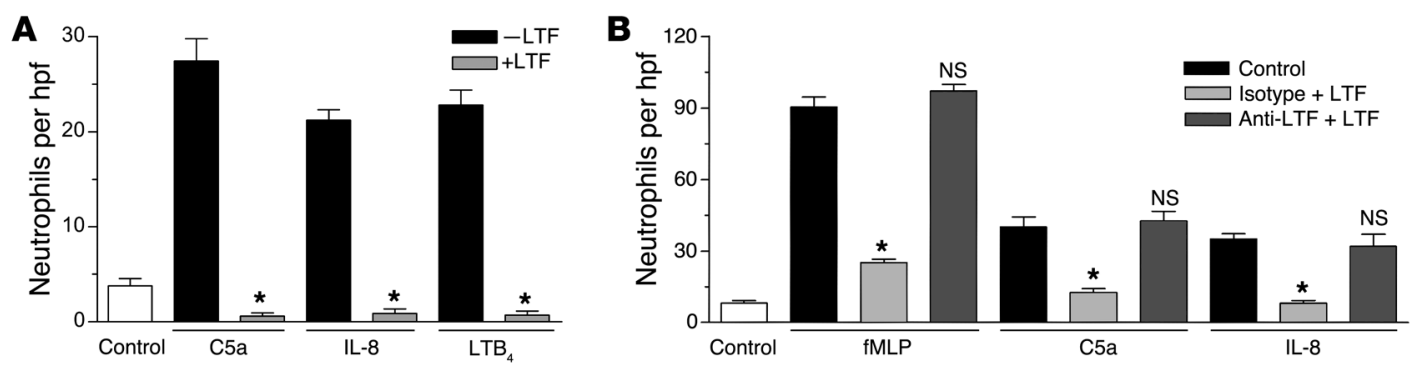

C
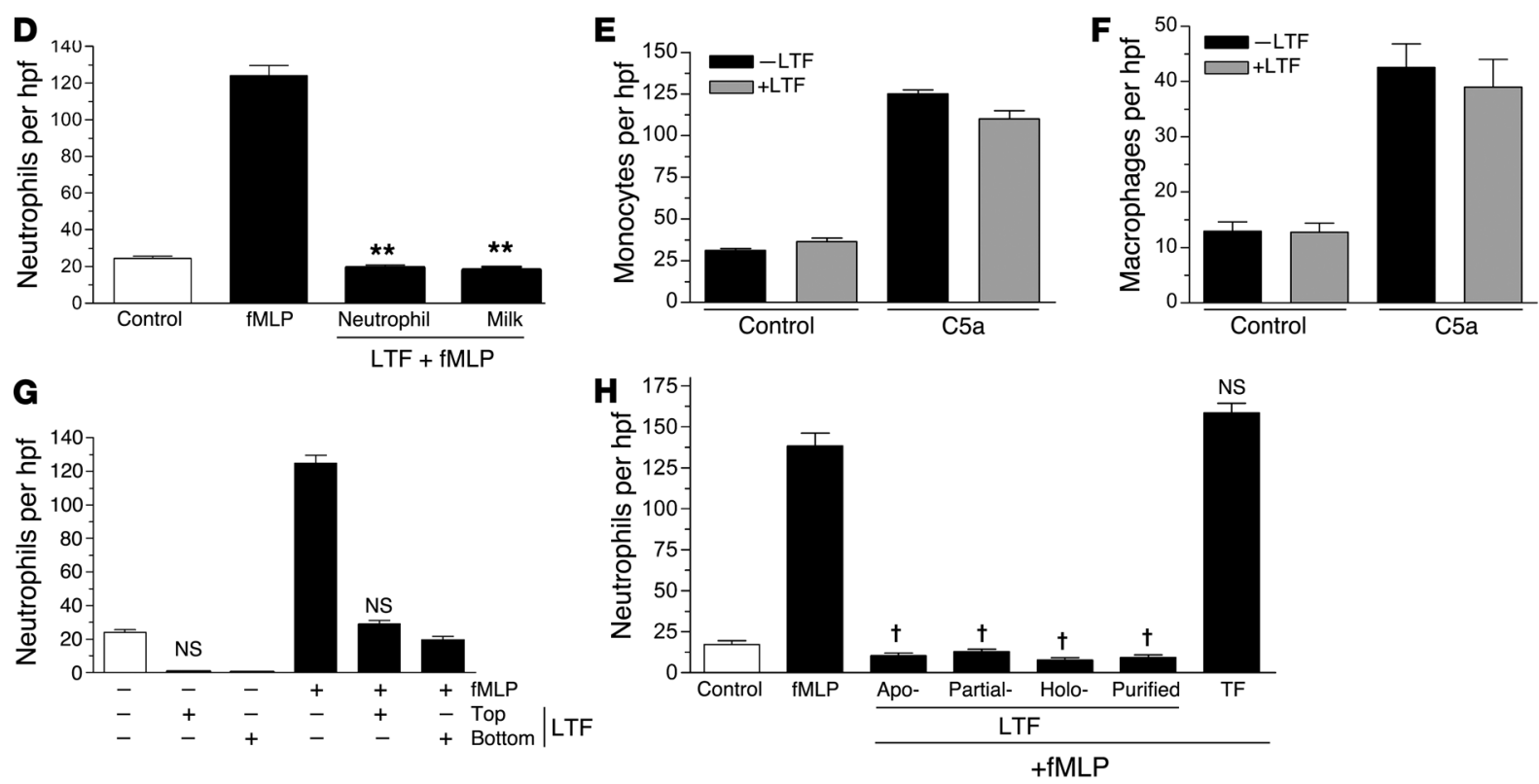

Figure 4

Neutrophil chemotaxis toward lactoferrin is irrespective of the chemoattractant used and its iron saturation status. (A) Neutrophil chemotaxis toward different chemoattractants. $n=3$; ${ }^{*} P<0.05$. (B) Neutrophil chemotaxis toward chemoattractants (control) or chemoattractants that were incubated with lactoferrin $(10 \mu \mathrm{g} / \mathrm{ml})$ followed by the addition of isotype or anti-lactoferrin monoclonal antibody (10 $\mu \mathrm{g} / \mathrm{ml})$. Antibodies were removed using magnetic IgG beads. $n=3$; ${ }^{*} P<0.05$, NS compared with chemoattractant control. (C) Immunoblot analysis of lysates of neutrophils incubated with or without biotinylated lactoferrin $(10 \mu \mathrm{g} / \mathrm{ml})$ at $37^{\circ} \mathrm{C}$ for 1 hour. (D) Neutrophil chemotaxis toward lactoferrin $(10 \mu \mathrm{g} / \mathrm{ml})$ purified from human neutrophils or human milk. ${ }^{* *} P<0.001$ vs. fMLP. C5a-induced monocyte $(\mathbf{E})$ or macrophage $(\mathbf{F})$ chemotaxis. $(\mathbf{G})$ Neutrophil migration in the presence of lactoferrin $(10 \mu \mathrm{g} / \mathrm{ml})$ in the top or bottom compartment of the Transwell insert $(n=3$; NS vs. corresponding $+\mathrm{LTF}$ controls). (H) Chemotaxis assay to determine neutrophil migration toward purified recombinant iron-depleted (Apo-), partially iron-saturated, and fully iron-saturated (Holo-) recombinant lactoferrin $(10 \mu \mathrm{g} / \mathrm{ml})$. Milk-purified lactoferrin and partially iron-saturated transferrin (TF; $10 \mu \mathrm{g} / \mathrm{ml})$ were added as control. $n=4 ;{ }^{\dagger} P<0.001$ compared with fMLP control. Error bars indicate SEM.

analysis of ${ }^{125}$ I-labeled apolactoferrin indicated, in accordance with earlier findings $(26,27)$, that lactoferrin bound to neutrophils via 2 classes of receptor that differ in affinity and number of binding sites per cell. We determined the higher-affinity receptors to be expressed at a density of 9,100 $\pm 2,500$ binding sites per cell, with an affinity of $350 \pm 65 \mathrm{nM}$, and the lower-affinity receptors to be expressed at a density of $2.5 \times 10^{6} \pm 0.7 \times 10^{6}$ per cell, with an affinity of $20 \pm 10 \mu \mathrm{M}$ (Supplemental Figure 2 ).

To determine whether the migration-inhibitory effects of lactoferrin were specific to neutrophils among professional phagocytes, we analyzed its effects on monocyte and macrophage migration in vitro. As shown in Figure 4, E and F, C5a-induced chemotaxis of mononuclear phagocytes was unimpaired by lactoferrin. We further assessed whether lactoferrin acted by inhibiting neutrophil migration or promoting neutrophil repulsion. In chemotaxis assays, in which we added lactoferrin to the upper chamber along with neutrophils, we observed inhibition of neutrophil migration toward $\mathrm{AMLP}$ and control medium (Figure 4G), suggesting that lactoferrin exerts a direct effect on neutrophils by inhibiting their migratory ability and not by forcing them to migrate in all directions away from the chemoattractant.

Neutrophil migration-inhibitory effects of lactoferrin are not related to its iron-binding properties and are demonstrable in vitro and in vivo. Iron and iron-associated molecules have been previously shown to play an important role in many immunomodulatory functions. Indeed, suppression of IL-1 release by monocytes is observed by purified iron-saturated lactoferrin, whereas an inhibition of GM colony-stimulating activity production by monocytes and macrophages correlated with the iron saturation status of lactoferrin (28-30). Therefore, we further examined whether differences in the iron saturation profile of lactoferrin affect its ability to inhibit neutrophil migration. Chemotaxis assays to determine neutrophil migration toward iron-depleted (apo-lactoferrin), partially iron-saturated, or fully iron-saturated (holo-lactoferrin) lactofer- 

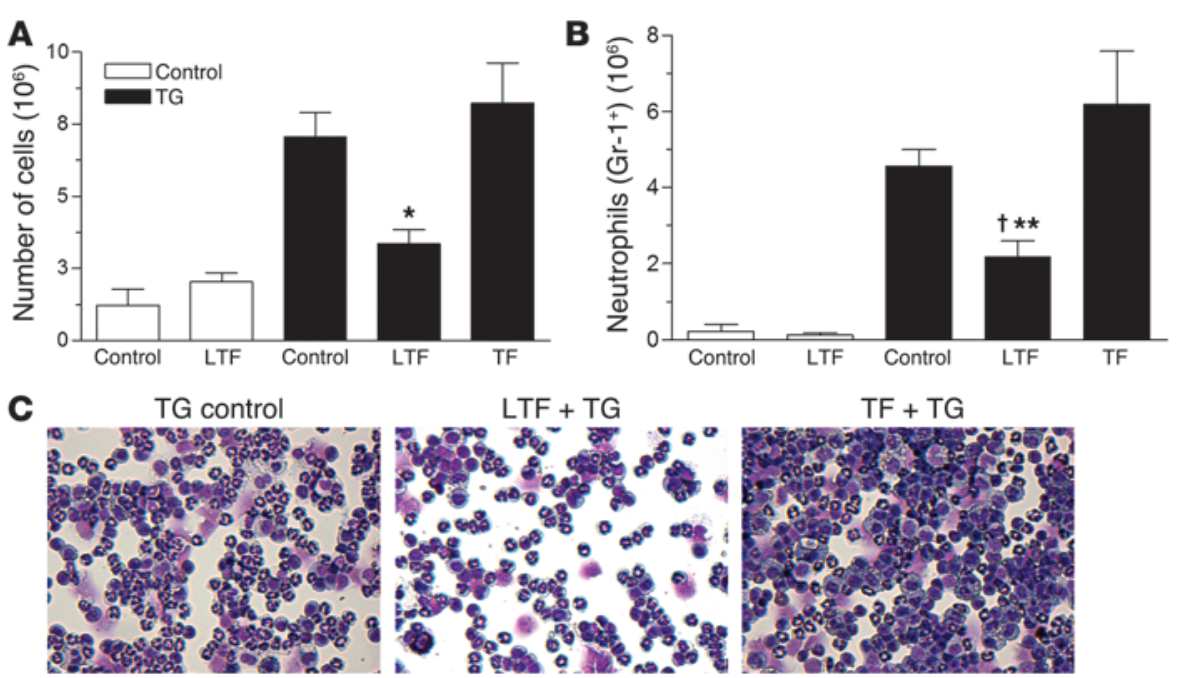

$\mathrm{LTF}+\mathrm{TG}$

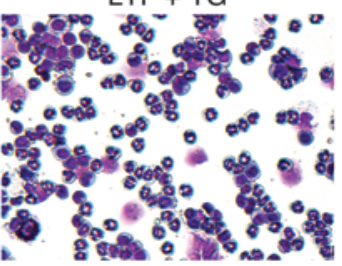

$\mathrm{TF}+\mathrm{TG}$
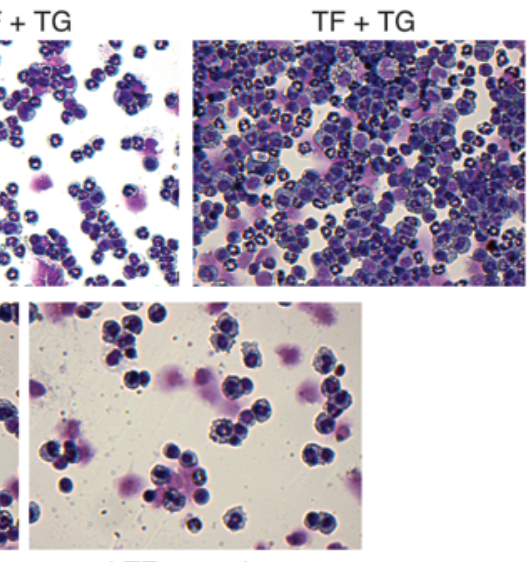

LTF control

\section{Figure 5}

Lactoferrin inhibits neutrophil migration in vivo. Total cell (A) or neutrophil number (Gr-1+; B) obtained from peritoneal lavage. ${ }^{*} P<0.05$ vs. transferrin; ${ }^{\dagger} P<0.05$ vs. thioglycollate (TG) control, ${ }^{* *} P<0.01$ vs. transferrin control. Error bars indicate SEM. (C) Characteristic cytospin images. Original magnification, $\times 400$, top; $\times 200$, bottom. rin revealed that the level of iron saturation was not responsible for the observed inhibition in neutrophil migration (Figure $4 \mathrm{H}$ ). Also, as lactoferrin belongs to the transferrin family of proteins sharing $74 \%$ sequence homology with transferrin (both of them are $80 \mathrm{kDa}$ cationic iron-binding glycoproteins), we reasoned that, if the underlying neutrophil migration-inhibitory mechanism of lactoferrin was rooted in its ability to chelate iron, transferrin might show similar effects on neutrophil migration. To explore this possibility, we performed chemotaxis assays in which neutrophils were induced to migrate toward AMLP in the presence of partially iron-saturated transferrin. Our results showed that transferrin, unlike lactoferrin, had no effect on neutrophil chemotaxis, further supporting the conclusion that the observed neutrophil migration-inhibitory effect is lactoferrin specific and is unlikely to require iron-chelating activity (Figure $4 \mathrm{H}$ ).

Having established the inhibitory effects of lactoferrin on neutrophil chemotaxis in vitro, we then used a murine peritonitis model to assess the effect of lactoferrin on leukocyte recruitment in vivo. Lactoferrin and transferrin were tested for their ability to affect thioglycollate-induced leukocyte recruitment to the peritoneal cavity. As shown in Figure 5, A and B, thioglycollate caused rapid recruitment of leukocytes compared with vehicle alone, and the recruited leukocytes were predominantly neutrophils (88\%). In the presence of lactoferrin, the total number of neutrophils recruited to the peritoneal cavity was reduced by $52 \%$ compared with control, whereas transferrin had no effect. Lactoferrin reduced specifically the proportion and number of neutrophils migrating into the cavity but did not affect recruitment of other types of leukocytes in response to thioglycollate (Figure $5 \mathrm{C}$ ). These results demonstrate that, similar to its effect on neutrophil chemoattraction in vitro, lactoferrin is a potent inhibitor of neutrophil migration in vivo.

Impairment of neutrophil activation profile by lactoferrin. Neutrophil migration involves activation, adhesion, and extravasation pro- cesses that are accompanied by gross changes in cell morphology: whereas nonactivated neutrophils are rounded, activated neutrophils acquire a polarized morphology with spreading and adhesion to the available substratum (15). In order to initially assess the effects of lactoferrin on neutrophil activation, we performed time-lapse video microscopy of neutrophils and recorded directly their activation morphology, cell spreading, and locomotion. During a 1-hour time course, lactoferrin-pretreated neutrophil populations stimulated with AMLP displayed a greater proportion of nonadherent cells as well as cells presenting a rounded, nonactivated morphology as compared with neutrophils treated with $\mathrm{AMLP}$ alone (Figure 6, A and B). These quantitative differences between lactoferrin-treated and untreated neutrophils stimulated with AMLP were reflected in the locomotion of the cells around the substratum, with lactoferrin-treated cells displaying markedly reduced movement.

Changes in cell morphology following stimulation with AMLP or other neutrophil agonists are characterized by a rapid increase in intracellular cytoplasmic calcium levels through mobilization of calcium from ER stores and activation of calcium influx channels of the plasma membrane, mediated by the inositol triphosphate $\left(\mathrm{IP}_{3}\right)$ and diacylglycerol/PLC (DAG/PLC) pathways (31-33). In order to determine whether the observed cell shape alterations following lactoferrin treatment are related to changes in intracellular calcium concentrations $\left(\left[\mathrm{Ca}^{2+}\right]_{i}\right)$, we measured the levels of $\left[\mathrm{Ca}^{2+}\right]_{i}$ in control and lactoferrin-treated cells in response to fMLP stimulation (1 nM or $10 \mathrm{nM})$. No changes were observed in the fMLP-mediated $\left[\mathrm{Ca}^{2+}\right]_{\mathrm{i}}$ response between control and lactoferrin-treated neutrophils, suggesting that lactoferrin acts downstream or independently of the mechanisms involved in intracellular calcium flux (Figure 6C).

As lactoferrin was shown to prevent neutrophil migration, we next explored whether it could also affect the neutrophil activation state. To this end, we chose to measure the expression of 2 
A
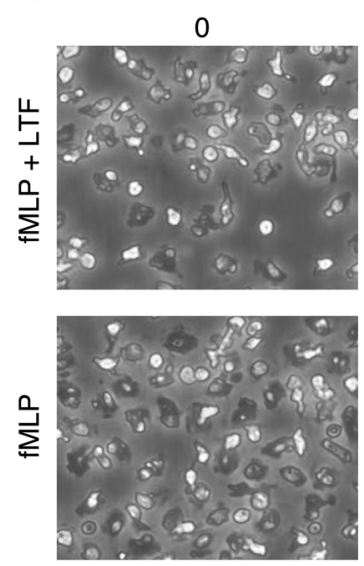

B
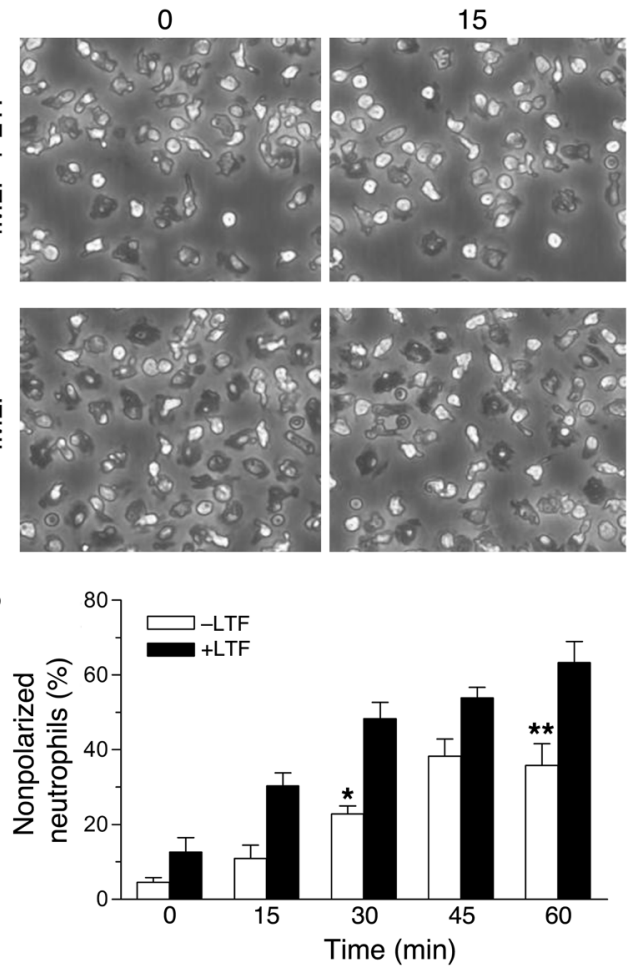

Time (min)
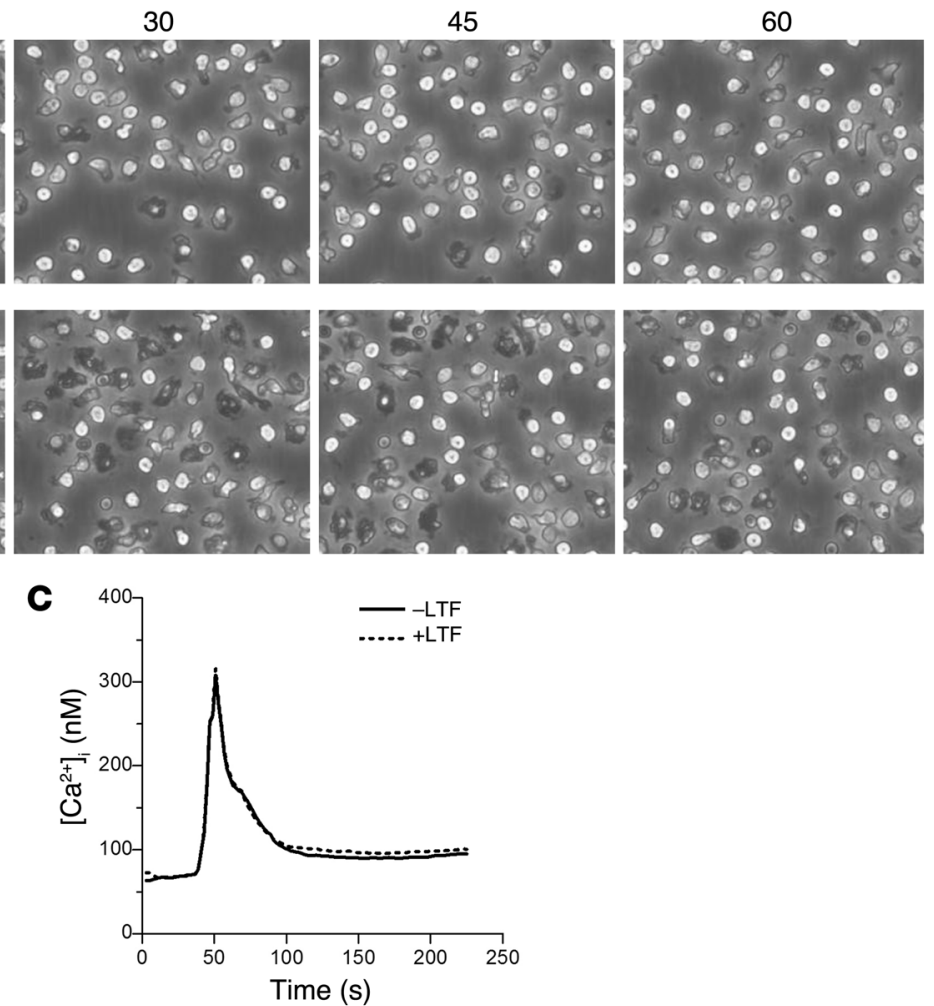

\section{Figure 6}

Effect of lactoferrin on neutrophil polarization morphology and spreading. (A) Time-lapse video microscopy frames of control or lactoferrin-pretreated neutrophils $\left(10 \mu \mathrm{g} / \mathrm{ml} ; 40\right.$ minutes at $\left.37^{\circ} \mathrm{C}\right)$ stimulated with $1 \mu \mathrm{M} \mathrm{fMLP}$ over a 1 -hour incubation time course. Original magnification, $\times 400$. (B) Quantification of neutrophils (nonpolarized) counted from 5 different fields; ${ }^{*} P<0.05,{ }^{* \star} P<0.01$ vs. corresponding + LTF control. Error bars indicate SEM. (C) Representative plot (of 3 independent experiments) showing measurement of $\left[\mathrm{Ca}^{2+}\right]_{\mathrm{i}}$ levels in neutrophils incubated in the presence or absence of lactoferrin $\left(10 \mu \mathrm{g} / \mathrm{ml} ; 30\right.$ minutes at $\left.37^{\circ} \mathrm{C}\right)$ followed by stimulation with $10 \mathrm{nM} \mathrm{fMLP}$.

known neutrophil activation-associated markers, CD62L (L-selectin) and CD11b, using 2-color flow cytometry. Upon activation, $\mathrm{CD} 62 \mathrm{~L}$ is cleaved from the neutrophil surface, whereas CD11b expression is upregulated following translocation from cytoplasmic granules to the cell membrane. Freshly isolated neutrophils were pretreated with lactoferrin and then exposed to the activation stimuli fMLP, TNF- $\alpha$, and PMA. As shown in Figure 7, A-D, we found that, in lactoferrin-treated neutrophils compared with control cells, CD62L expression was significantly higher, whereas CD11b levels were lower. These effects were common to all activation stimuli used. Transferrin-treated neutrophils were also included but showed no significant differences compared with control cells. It is noteworthy that the lactoferrin effect was also evident when PMA, a specific PKC activator, was used as an agonist, indicating that lactoferrin acts downstream of PKC and not on pathways involved in PKC activation and $\mathrm{Ca}^{2+}{ }_{i}$ responses, such as the $\mathrm{IP}_{3}$ and DAG/PLC pathways. This finding prompted us to investigate putative downstream targets of PKC involved in the late signaling cascades following neutrophil activation that also regulate cell motility and actin reorganization. Such cascades involve the activation of MAP family kinases (34), and we therefore examined the phosphorylation of p44/42 (ERK1 and ERK2) MAPKs. Whereas in untreated neutrophils, ERK1 and ERK2 were phosphorylated following fMLP stimulation $(100 \mathrm{nM})$, lower levels of phosphorylated ERK1/2 were observed in neutrophils that had been pretreated with lactoferrin prior to stimulation with fMLP (Figure 7E). Collectively, these data suggest that lactoferrin has a clear impact on neutrophil activation, including impairment of neutrophil degranulation, inhibition of expression of $\beta_{2}$ integrins, and reduction of activation of intracellular kinases, with profound effects on cell migration and motility.

Induction of apoptosis upregulates lactoferrin expression and release in diverse cell types. Pursuing our initial hypothesis, which was strengthened by early observations that inhibition of neutrophil migration by BL cells appeared to be correlated with BL cell apoptosis (Figure 1E), we assessed lactoferrin expression following induction of apoptosis in a panel of cells of diverse lineages. By transcriptional analysis using RT-PCR, we found that lactoferrin was expressed, as reported previously (35), by MCF-7 mammary epithelial cells in their viable state but not by Jurkat, BL2, or A549 cells. Upon apoptosis induction, lactoferrin expression was upregulated in MCF-7 cells and expressed de novo in Jurkat, BL2, and A549 cells (Figure 8). More specifically, lactoferrin was transcribed de novo early after induction of apoptosis in A549 cells by either $100 \mathrm{nM}$ etoposide or $1 \mu \mathrm{M}$ staurosporine (Figure 8B). Levels of lactoferrin induced by etoposide were reduced in cells treated in the presence of the broad-spectrum caspase inhibitor zVAD-fmk, which prevented apoptosis induction (Figure 8C). The link between lactoferrin expression and apoptosis induction was further supported by the effects of the apoptosis inhibitor Bcl-2. 
A
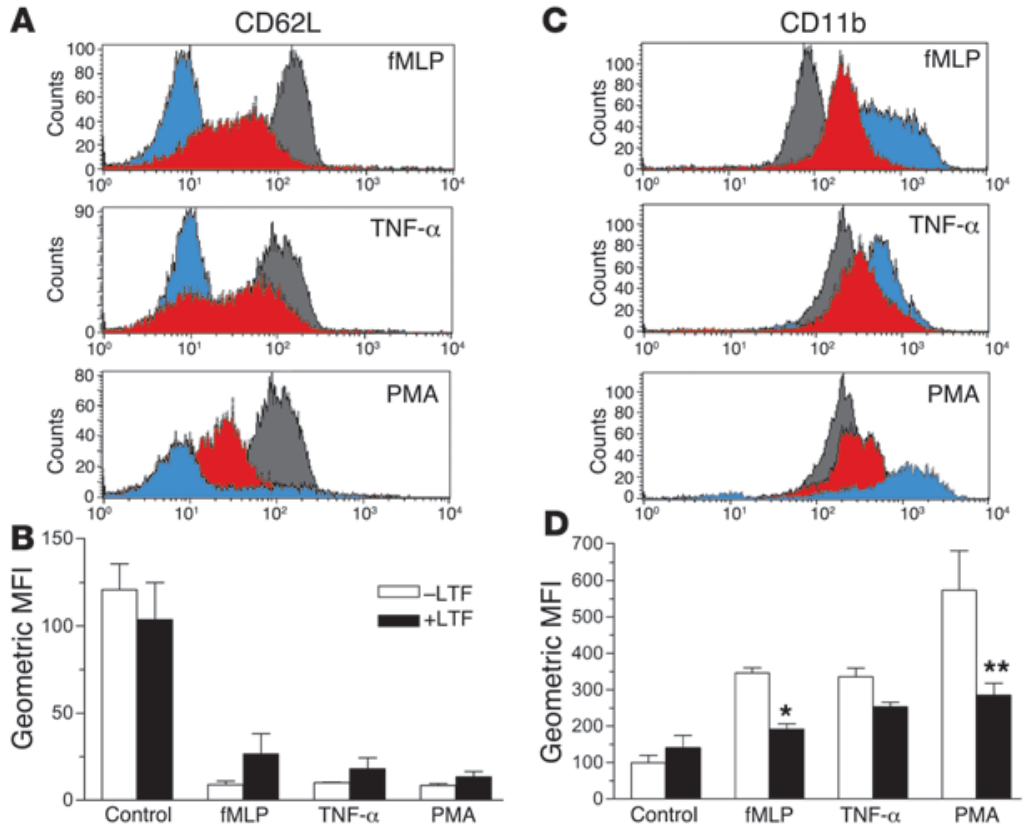

E

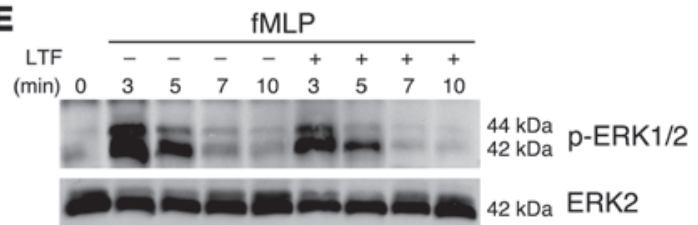

C
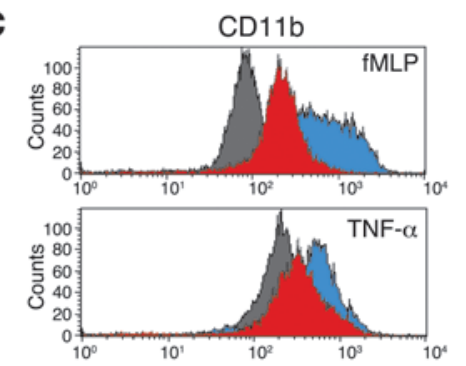

\section{Figure 7}

Effect of lactoferrin on neutrophil activation status. The expression of CD62L (A and B) and CD11b (C and D) was assessed in fMLP- $(100 \mathrm{nM})$, TNF- $\alpha-(1 \mathrm{ng} \mathrm{ml})$, or PMA-stimulated (100 nM) neutrophils (30 minutes at $\left.37^{\circ} \mathrm{C}\right)$ that were preincubated $\left(40\right.$ minutes at $\left.37^{\circ} \mathrm{C}\right)$ in the presence or absence of lactoferrin $(10 \mu \mathrm{g} / \mathrm{ml})$. Representative flow cytometry overlays of CD62L (A) and CD11b (C) expression in control (gray) and stimulated neutrophils (lactoferrin-treated: red; untreated: blue). $n=3 ;{ }^{\star} P<0.05,{ }^{\star \star} P<0.01$. Error bars indicate SEM. (E) Western blot analysis to determine levels of ERK1/2 phosphorylation. Neutrophils were incubated with lactoferrin $\left(10 \mu \mathrm{g} / \mathrm{ml} ; 40\right.$ minutes at $\left.37^{\circ} \mathrm{C}\right)$, followed by stimulation with fMLP $(100 \mathrm{nM})$ for the indicated times. Membrane was stripped and reprobed for total ERK2. Results are representative of 3 independent experiments.
BL cells expressing exogenous Bcl-2 that provided protection from apoptosis expressed lower levels of lactoferrin upon exposure to staurosporine than did their parental counterparts (Figure 8, A and D). Not only was apoptosis-related lactoferrin expression demonstrated at the transcriptional level, lactoferrin protein was also recovered from supernatants of cells undergoing apoptosis (Figure 8D). Treatment of A549 cells with brefeldin A, which interferes with intracellular transport of newly synthesized proteins, resulted in inhibition of apoptosis-induced lactoferrin release, providing further evidence for de novo synthesis and secretion of lactoferrin by cells undergoing apoptosis (Figure 8E). An analogous effect was also evident from supernatants obtained from primary lymphocytes induced to become apoptotic in the presence of $1 \mu \mathrm{M}$ staurosporine. Finally, immunoblotting analyses and chemotaxis assays using supernatants of BL cells undergoing primary necrosis further revealed that the release of lactoferrin is not linked to necrosis but that lactoferrin is expressed and actively released from cells as a consequence of activation of their apoptosis program (Figure 8F and Supplemental Figure 3).

\section{Discussion}

Apoptosis plays a key role in regulating cell populations through programmed cell death, an intrinsically non-phlogistic process that contrasts with accidental, necrotic cell death, which has proinflammatory consequences. Defining the properties of apoptotic cells that contribute to the noninflammatory or antiinflammatory nature of the apoptosis program is critical to our understanding of this fundamental biological process. We have now identified lactoferrin as a cell-autonomous antiinflammatory mediator that is produced by cells of diverse lineages undergoing apoptosis. Furthermore, these studies demonstrate a hitherto unrecognized immunomodulatory function of lactoferrin: to inhibit directly the migration of neutrophil granulocytes. Lactoferrin is therefore a constitutive antiinflammatory component of apoptotic cells that, in addition to its known antiinflammatory properties, militates against the proinflammatory recruitment of granulocytes to sites of apoptosis.

First discovered in milk almost 70 years ago, lactoferrin is a highly pleiotropic iron-binding glycoprotein closely related to transferrin that is a well-known constituent of exocrine secretions and secondary granules of neutrophils. It has many antiinflammatory and immunoregulatory properties, and the majority of these are not related to its ability to chelate iron, although some of its bacteriostatic features are dependent on iron binding $(36,37)$. Its ability to inhibit neutrophil migration, as described here, is an additional antiinflammatory feature of the molecule that is independent of its iron-chelating activity. In addition to its well-established antimicrobial properties, lactoferrin can inhibit proinflammatory responses not only through its ability to bind to key components of bacteria and viruses, but also through its direct activity on innate immune cells and molecules $(36,37)$. Thus, lactoferrin can inhibit production of proinflammatory mediators such as TNF- $\alpha$ and IL- $6(38,39)$ and can promote production of antiinflammatory mediators including IL-10, IL-4, and TGF- $\beta 1(40,41)$.

The identification of specialized high- or low-affinity lactoferrin receptors on human neutrophils provides an initial mechanistic insight into how lactoferrin exerts its inhibitory effect on the neutrophil migration machinery. This is in accordance with our 

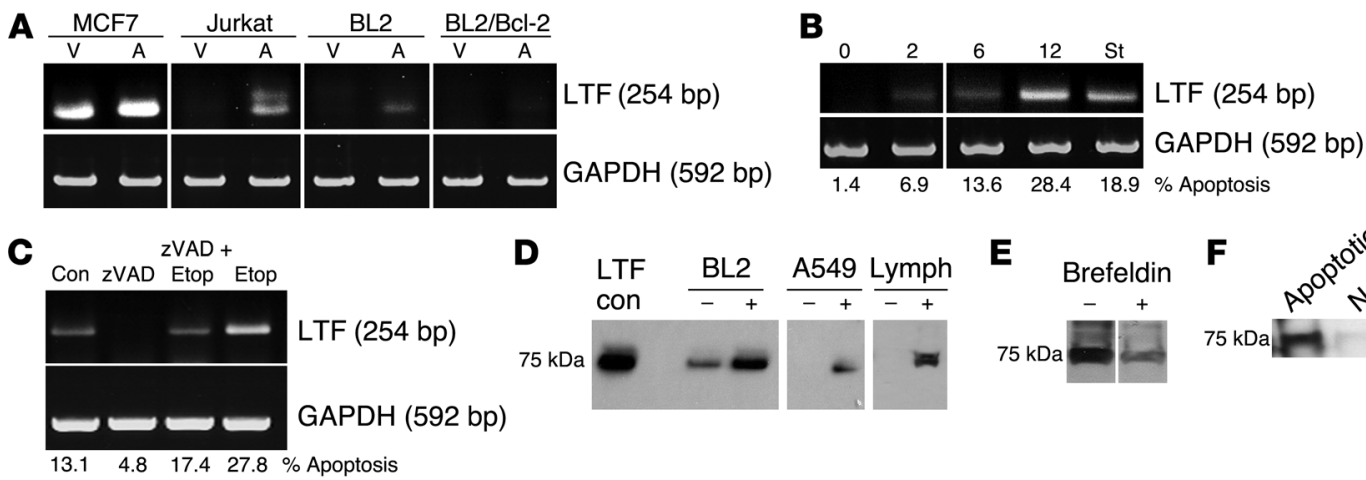
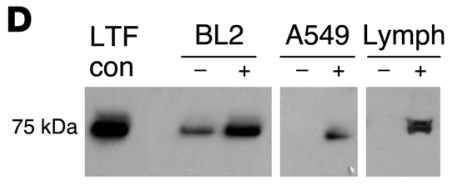

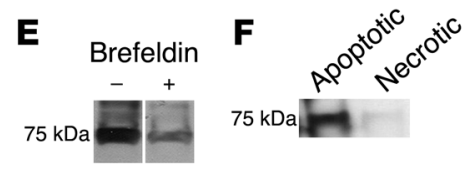

\section{Figure 8}

Induction of apoptosis upregulates lactoferrin expression and release. (A) RT-PCR analysis in cell lines stimulated to undergo apoptosis (A) and unstimulated controls (V). MCF7 cells transfected with caspase-3 (25.4\% apoptosis; $100 \mu$ M etoposide, 20 hours), Jurkat (18.4\% apoptosis; $1 \mu \mathrm{M}$ staurosporine, 3 hours), BL2 (12.46\% apoptosis), and BL2/Bcl-2 (7.42\% apoptosis; $1 \mu \mathrm{M}$ staurosporine, 1 hour). The lanes were run on the same gel but, where indicated by the vertical lines, were noncontiguous. (B) Lactoferrin expression in A549 cells at defined time points (hours) following stimulation with $100 \mu \mathrm{M}$ etoposide or $1 \mu \mathrm{M}$ staurosporine. (C) Addition of pan-caspase inhibitor ZVAD-fmk (100 $\mu \mathrm{g} / \mathrm{ml})$ for 12 hours in order to prevent etoposide-induced apoptosis in A549 cells. (D) Immunoblot analysis of cell supernatants from: BL2 and primary lymphocytes in the presence $(+)$ or absence $(-)$ of staurosporine $(1 \mu \mathrm{M})$ in serum-free conditions for 1 hour. A549 cells were stimulated with $(+)$ or without $(-) 100 \mu \mathrm{M}$ etoposide for 5 hours. All samples were run on the same gel. Noncontiguous samples of A549 cells and lymphocytes (Lymph) are indicated by the vertical lines. (E) A549 cells were induced to become apoptotic (100 $\mu \mathrm{M}$ etoposide; 20 hours) in the presence or absence of brefeldin A $(1 \mu \mathrm{g} / \mathrm{ml})$, a protein release inhibitor. (F) Immunoblot analysis of cell supernatants from control BL2 cells $\left(1 \times 10^{6} / \mathrm{ml}\right)$ induced to undergo apoptosis ( $1 \mu \mathrm{M}$ staurosporine, 1 hour) or primary necrosis $\left(56^{\circ} \mathrm{C}, 1\right.$ hour) in serum-free conditions. St, staurosporine; con; control; Etop, etoposide.

results demonstrating that lactoferrin binds directly to neutrophils and impinges on intracellular signaling events coupled to neutrophil activation, rather than interacting with chemoattractants and modulating their activity. Moreover, the latter possibility was further excluded by the fact that the observed inhibitory effect of lactoferrin was (a) specific to neutrophil, not monocyte, migration, (b) observed with a diversity of chemoattractants, and (c) not directly neutralized by chemoattractants. Consistent with other studies $(26,27)$, our results demonstrated 2 classes of lactoferrin receptor on the surface of human neutrophils. Our results indicate that a relatively high-affinity receptor is expressed at relatively low density and that a relatively low-affinity receptor is expressed at relatively high density. However, the detailed characterization of the lactoferrin receptor(s) and dissection of downstream signaling pathways remain a significant challenge, as lactoferrin has been extensively reported to interact with a range of molecules and receptors in a cell-specific manner and therefore has the potential to elicit different signaling cascades in different cell types. Indeed, many researchers over many years have attempted the detailed characterization of lactoferrin receptors from various cell types with only partial success, and many candidate receptors have been proposed for different cell types. Importantly, as has been suggested elsewhere (42), critical difficulties in the identification of specific lactoferrin receptors stem from the cationic nature of the lactoferrin protein, allowing it to bind to anionic molecules found in virtually all cell types.

Here, we have observed several effects of lactoferrin on cell activation with clear implications for migration, adhesion, and motility of neutrophils. The initial phase of neutrophil activation following agonist stimulation is characterized by a rapid increase in $\left[\mathrm{Ca}^{2+}\right]_{\mathrm{i}}$, which in turn triggers the activation of PKC as well as a range of calcium-dependent signaling pathways that control key neutrophil effector functions, including degranulation, cytoskeletal rearrangements, and cell migration (32, 43-45). Our data clearly suggest that the observed lactoferrin-mediated inhibitory effects on neutrophil chemotaxis could be attributed to modulation of molecules other than those involved in the $\mathrm{Ca}^{2+}{ }_{i}$ response following agonist stimulation. In addition, analysis of the expression of early activation markers such as CD62L and CD11b following stimulation with diverse neutrophil agonists, including PMA, a specific synthetic intracellular activator of PKC, further suggests that lactoferrin acts downstream or independently of the PKC pathway, affecting signaling cascade components of the later phases of neutrophil activation. This notion was strengthened by our observation that lactoferrin inhibited the phosphorylation of p44/42 (ERK1 and ERK2) MAPKs, indicating that its action is mediated, at least in part, via the MAPK pathway, a key pathway downstream of PKC with a crucial role in the regulation of cytoskeletal rearrangement and cell adhesion (46-48). The previously reported specific interaction of lactoferrin with the calciumcalmodulin complex $\left(\mathrm{Ca}^{2+} / \mathrm{CaM}\right)$ provides further insight into the potential intracellular signaling targets of lactoferrin (49). The $\mathrm{Ca}^{2+} / \mathrm{CaM}$ complex is formed following the increase in $\left[\mathrm{Ca}^{2+}\right]_{\mathrm{i}}$ and $\mathrm{PKC}$ activation and regulates the activity of a number of pathways involved in cell adhesion and migration, including the ERK1/2 kinases (50). Indeed, the use of specific inhibitors of calmodulin activity has been demonstrated to mimic the effect of lactoferrin - inhibition of neutrophil migration - reported here (51-53).

Lactoferrin has been shown previously to bind to receptors on mononuclear phagocytes and to inhibit proinflammatory responses via NF-кB $(39,54,55)$. Taken together with the evidence that apoptotic cells can suppress proinflammatory responses of mononuclear phagocytes and can elicit antiinflammatory responses by these cells $(10,11)$, our results indicate that it is now reasonable to suspect that these effects are mediated, at least in part, by lactoferrin produced by apoptotic cells. However, the involvement of the NF-кB pathway in the inhibition of neutrophil migration seems unlikely, since lactoferrin-mediated inhibition of chemotaxis of 
neutrophils treated with gliotoxin, a specific NF-кB inhibitor, was found to be identical to that of untreated cells (data not shown).

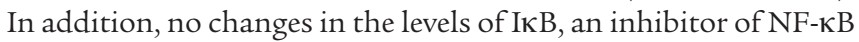
that is degraded following NF- $\mathrm{KB}$ activation, were observed in Western blot analysis of fMLP-stimulated neutrophils treated with or without lactoferrin (data not shown).

In general terms, in professional phagocytes, sensing mechanisms that are not yet well defined allow these cells to navigate to apoptotic cells through chemotactic processes involving lipid signaling molecules and classical chemokine mechanisms $(1,2)$. It is noteworthy that of the 2 categories of professional phagocytes - mononuclear (monocytes and macrophages) and polymorphonuclear (granulocytes) - apoptotic cells attract mononuclear phagocytes selectively (12). Indeed, the lack of recruitment of granulocytes to apoptotic zones is a hallmark of the non-phlogistic apoptosis program, distinguishing normal areas of cell death from sites of accidental or pathological tissue damage or infection. Recent evidence suggests that certain recombinant preparations of lactoferrin have the potential to chemoattract monocytes (56). Although we failed to observe monocyte attraction to lactoferrin in our studies with milk-derived lactoferrin, these results indicate that lactoferrin has the potential to function in the selective attraction of monocytes but exclusion of granulocytes from sites of apoptosis. Our observation that lactoferrin, released into the supernatants of apoptotic cells, is able to inhibit the migration of neutrophils, demonstrates not only that physiological concentrations of lactoferrin are functional in mediating this effect but also that apoptotic cells are active in producing a factor that can potently suppress migration of neutrophils, the major subset of professional phagocytes among circulating leukocytes, to sites of apoptosis. Although it is clear that the secretory events inhibited by brefeldin A treatment (transport from the ER and Golgi network) are important for the release of lactoferrin from apoptotic cells, further work will be required to elucidate the details of this secretory process - including whether lactoferrin is transported directly from Golgi membranes for release from the cell surface.

While neutrophils may lack the sensing mechanisms to guide them to sites of apoptosis, the constitutive production of a factor that blocks neutrophil migration to such sites is likely to be important when the apoptosis program is activated in the presence of signals that promote neutrophil recruitment during inflammatory responses. In this context, it is noteworthy that lactoferrin is active in inhibiting IL-8 production by endothelial cells (57). Furthermore, lactoferrin's ability to inhibit neutrophil migration is likely to be important in the resolution of acute inflammation. Thus, our results suggest that lactoferrin arising from the secondary granules of neutrophils and from apoptotic cells constitutes a negative feedback component that limits the influx of neutrophils to inflammatory sites. We would speculate that neutrophils undergoing apoptosis en route to resolution of inflammation would release lactoferrin as do other apoptotic cells but would be unlikely to be required to synthesize the protein de novo. The negative regulatory activity of lactoferrin described here places it as one of the few molecules, alongside lipoxins, netrin-1, and annexin-1, that negatively regulate neutrophil migration $(21,58,59)$. More importantly, based on the high specificity of its migration-inhibitory properties to neutrophils, lactoferrin is identified here as a promising therapeutic target for a range of chronic inflammatory conditions, including vasculitis, pulmonary fibrosis, and ischemia/reperfusion injury, that are characterized by excessive neutrophil infiltration leading to neutrophil-mediated host tissue damage and remodeling (19).

Since the properties of lactoferrin extend well beyond its ability to regulate infection, immune responses, and inflammation, the link established here between lactoferrin production and apoptosis has many additional implications. First, lactoferrin's ability to act as a growth factor $(60,61)$ extends evidence coupling the apoptosis program with tissue repair responses $(62,63)$. Second, additional recent evidence suggests that its protease activity may be instrumental in activating the caspase cascade. In particular, endogenous lactoferrin has been reported by 2 groups to induce apoptosis through activation of caspase-3 $(64,65)$. It is tempting to speculate that the de novo synthesis of lactoferrin by cells triggered to undergo apoptosis in our studies is linked to the initiation of the apoptosis program as well as to its antiinflammatory features. Therefore, lactoferrin may have multiple properties in apoptosis: (a) regulating the initiation of the program, (b) influencing repair in the tissue microenvironment, and (c) promoting the non-phlogistic nature of the process.

Lactoferrin's functions in relation to tumor biology are currently unclear. Proteolyzed forms of exogenous lactoferrin have been reported to have proapoptotic and antitumor activities. In addition, lactoferrin appears to promote antitumor host immune responses (37), and activation of antigen-presenting cells has recently been reported using high doses of recombinant lactoferrin produced in Aspergillus (56). Its observed effects on cell growth are inconsistent, and both growth-promoting and growth-inhibiting effects have been reported $(60,61,66,67)$, suggesting the possible importance of tissue context. Since lactoferrin has potent ability to inhibit neutrophil migration, it seems likely that in tumors in which neutrophils play a supportive role, limitation of neutrophil infiltration through lactoferrin administration could be therapeutically beneficial. However, in tumors in which neutrophils are absent, we propose that, given the known antitumor effects of neutrophils (68-71), encouragement of neutrophil infiltration through inhibition of lactoferrin may effect tumor destruction. Our results might predict that tumors in which apoptosis is prominent would produce lactoferrin in situ. While this suggestion requires proper investigation, at least in one category, BL, a high-grade malignancy in which high-rate apoptosis occurs, in situ production of lactoferrin protein has been known for many years (72).

In conclusion, we describe a novel homeostatic function for the highly pleiotropic immunomodulatory glycoprotein lactoferrin. We demonstrate that lactoferrin production is closely coupled to the fundamental cell death program, apoptosis. In this respect, lactoferrin is much more generally expressed than previously realized. Our results show that lactoferrin endows apoptotic cells with antiinflammatory properties, including the capacity to inhibit neutrophil migration. Given the multifunctional abilities of lactoferrin, these results have broad implications for the influence of apoptotic cells on multiple physiological processes, including cell growth, differentiation, and innate and adaptive immune responses, as well as the pathological processes of inflammatory and malignant diseases.

\section{Methods}

Antibodies and reagents. The following antibodies and reagents were used in this study: rabbit polyclonal anti-human lactoferrin IgG antibody (SigmaAldrich), mouse monoclonal anti-human lactoferrin antibodies (LF-2B8, AbD Serotec; imab75 and imab77, ImmunoSolv), rabbit polyclonal immu- 
noglobulin (IgG) negative control (Dako), IgG1 isotype control (SigmaAldrich), allophycocyanin-conjugated (APC-conjugated) anti-CD11b (mIgG1; BD), FITC-conjugated anti-CD62L (mIgG1; AbD Serotec), purified human lactoferrin from milk (Sigma-Aldrich), purified human lactoferrin from neutrophils (Athens Research and Technology), recombinant human lactoferrin (Sigma-Aldrich), human recombinant apolactoferrin/ hololactoferrin (ProSpec), purified human transferrin (Sigma-Aldrich), recombinant human TNF- $\alpha$ (R\&D Bioscience), PMA (Sigma-Aldrich), fMLP (Sigma-Aldrich), C5a (Sigma-Aldrich), IL-8 (Sigma-Aldrich), LTB 4 (Sigma-Aldrich), brefeldin A (Sigma-Aldrich), staurosporine (SigmaAldrich), and gliotoxin (Sigma-Aldrich). For lactoferrin absorption chemoattractants, each chemoattractant was incubated with purified human milk lactoferrin $(10 \mu \mathrm{g} / \mathrm{ml})$, and a mouse monoclonal anti-human lactoferrin antibody (LF-2B8; $10 \mu \mathrm{g} / \mathrm{ml}$ ) or isotype control was added. Antibodies were completely removed by BioMag goat anti-mouse IgG (QIAGEN) magnetic beads, and the efficiency of antibody removal was assessed by analysis of the preabsorbed chemoattractants by anti-mouse IgG ELISA (data not shown). Furthermore, the depleted antibody was readily recovered from the beads (data not shown).

Cell isolation. Fresh human venous blood was collected from volunteers according to the Royal Infirmary of Edinburgh (Scotland) Research Ethics Committee (approval 1702/95/3/11), and mononuclear and polymorphonuclear (PMN) leukocytes were isolated as previously described (73). Neutrophils represented more than $95 \%$ of isolated PMN cells. Monocytes (>90\% CD $14^{+}$cells) were positively selected from isolated mononuclear leukocytes using CD14 magnetic beads (Miltenyi Biotec). Human monocyte-derived macrophages were obtained following culture of monocytes for 6 days in Iscove's modified Dulbecco's medium (IMDM) containing $10 \%$ autologous serum.

Chemotaxis assay. In vitro leukocyte chemotaxis was measured following a well-established transfilter cell migration assay, as previously described (12) using polyvinyl uncoated Transwell inserts (5 $\mu \mathrm{m}$ pore size; Costar, Corning). Time of incubation $\left(37^{\circ} \mathrm{C} ; 5 \% \mathrm{CO}_{2}\right)$ varied for cell type (neutrophils: 60 minutes; monocytes: 90 minutes; macrophages: 4 hours). Unless otherwise stated, lactoferrin was used at $10 \mu \mathrm{g} / \mathrm{ml}$. Chemotactic agents included fMLP (100 nM; Sigma Aldrich), C5a (6.25 ng/ml; Sigma Aldrich), IL-8 (50 nM; R\&D Systems), and LTB 4 (100 nM; Sigma Aldrich). For neutralization experiments, rabbit polyclonal anti-human lactoferrin antibody (Sigma Aldrich) or negative control (Dako) were used. Filters were observed using an inverted microscope (Zeiss Axiovert 25), and relative cell migration was determined by enumerating the number of migrated cells in 10 random high-power $(\times 400)$ fields.

shRNA lentiviral transduction of BL cells. Lactoferrin expression was downregulated using shRNA lentiviral vectors (MISSION; Sigma-Aldrich). Briefly, lactoferrin-targeted shRNA lentiviral plasmids (pLKO.1-puro) were cotransfected with ViraPower Lentiviral packaging mix (pLP1, pLP2, pLP-VSV-G; Invitrogen) to 293FT cells using Lipofectamine LTX (Invitrogen). BL2 cells were transduced with the shRNA-expressing lentivirus, and stable cell lines were generated by selection with puromycin ( $2 \mu \mathrm{g} / \mathrm{ml}$; Sigma-Aldrich).

RT-PCR analysis. Total RNA was extracted (RNeasy kit; QIAGEN) and reverse transcribed $(2 \mu \mathrm{g})$ using SuperScript III RT (Invitrogen). Resulting cDNAs were used as template in PCR experiments at a concentration of $1 \mathrm{ng} / 50 \mu \mathrm{l}$ of PCR mixture. The primers used were: forward lactoferrin (5'-TGTCTTCCTCGTCCTGCTGTTCCTCG-3') and reverse lactoferrin ( $5^{\prime}$-CTGCCTCGTATATGAAACCACCATCAA-3'), forward GAPDH primer (5'-CGACAGTCAGCCGCATCTTCTTTTGCGTCG-3') and reverse GAPDH primer (5'-GGACTGTGGTCATGAGTCCTTCCACGATAC-3'). Cycle parameters (lactoferrin: 40 cycles; GAPDH: 28 cycles) were: denaturation $94^{\circ} \mathrm{C}$ for 1 minute, primer annealing at $67^{\circ} \mathrm{C}$ (lactoferrin) or $50^{\circ} \mathrm{C}(\mathrm{GAPDH})$ for $1 \mathrm{~min}$ ute, and extension at $72^{\circ} \mathrm{C}$ for 45 seconds, with a first denaturation step at $94^{\circ} \mathrm{C}$ for 7 minutes and a final extension at $72^{\circ} \mathrm{C}$ for 5 minutes. Purified PCR products (QIAquick gel extraction kit; QIAGEN) were sequenced to confirm validity by the Sequencing Service of the School of Life Sciences, University of Dundee, using Applied Biosystems BigDye 3.1 chemistry on an Applied Biosystems model 3730 automated capillary DNA sequence analyzer.

Peritonitis model. All animal procedures were carried out under a UK Home Office Animals (Scientific Procedures) Act 1986 project licence. Mice (8- to 12 -week-old female C57BL/ 6 mice; $n=7$ per group) were injected i.p. with purified human lactoferrin or transferrin (500 ng in saline/0.1\%; BSA Sigma Aldrich) or saline $/ 0.1 \%$ BSA alone followed by a second i.p. injection with $1 \%$ thioglycollate $(500 \mu \mathrm{l})$ or saline/ $0.1 \%$ BSA after 20 minutes. Recruited leukocytes were harvested after 4 hours by peritoneal lavage with ice-cold saline containing $2 \mathrm{mM}$ EDTA. Harvested cells were counted using a NucleoCounter (ChemoMetec), which excluded nonnucleated cells. To determine the number of neutrophils $\left(\mathrm{Gr}-1^{+}\right)$, cells were immunolabeled with PE-conjugated anti-mouse Ly6-Gr-1 and counted using Flow-Count beads (Beckman Coulter).

Histology and immunohistochemistry. Six- to 10-week-old BALB/c SCID mice were injected i.p. with $10^{7} \mathrm{BL} 2$ cells. Tumors developed i.p. within 2 months of injection. Mice were sacrificed and tumors excised. For positive control, $\mathrm{BALB} / \mathrm{c}$ mice were immunized with sheep red blood cells and spleens harvested and frozen 7 days after i.p. injection. Immunohistochemistry was performed on frozen acetone-fixed sections $(5 \mu \mathrm{m})$ of BL or spleen tissues using biotinylated anti-mouse $\mathrm{Gr}-1$ antibody $(10 \mu \mathrm{g} / \mathrm{ml}$; BioLegend) or isotype control ( $\mathrm{AbD}$ Serotec). Nonspecific adsorption of antibodies was blocked using serum-free Protein Block (Dako). Reactions were amplified using VECTASTAIN Elite ABC avidin-biotinylated peroxidase complexes (Vector Laboratories). Hematoxylin was used as counterstain.

Flow cytometry. Unless otherwise stated, cells were suspended in PBS containing $5 \%$ normal mouse serum or $0.1 \%$ BSA, and all antibody incubations were performed for 20 minutes on ice. Mouse neutrophils were defined based on the expression of Gr-1 epitope using PE-conjugated rat anti-mouse Ly6G (Gr-1; eBioscience). For the assessment of neutrophil activation, the following antibodies were used: FITC-conjugated antiCD62L (FMC46, mIgG2b; AbD Serotec) and APC-conjugated anti-CD11b (ICRF44, mIgG1; BD). Isotype controls included mouse IgG1:FITC (AbD Serotec), mouse IgG1:APC (BD), and rat IgG2b:PE (eBioscience). Cell apoptosis was determined by labeling with annexin $\mathrm{V}$ and propidium iodide. Samples were analyzed using a BD FACSCalibur or FACScan cytometer, and data were analyzed using BD CellQuest software.

Size fractionation and ion exchange chromatography. Size fractionation of BL2 cell conditioned media was performed using filters with specific molecular weight cutoff sizes (Amicon Centrifugal filters YM-50 and YM-100; Millipore), following the manufacturer's instructions. Ion exchange chromatography was carried out using Q Sepharose Fast Flow beads (Sigma-Aldrich). Beads were washed with neutralizing buffer, and bound proteins were then eluted by addition of $10 \mathrm{mM} \mathrm{NaAc}, 0.5 \mathrm{M} \mathrm{NaCl}, \mathrm{pH}$ 4. BL2 cell-conditioned medium or control medium (RPMI 1640) was mixed with the beads and incubated at room temperature for 5 minutes. Samples were centrifuged ( $300 \mathrm{~g}, 5$ minutes) and supernatants stored. Beads were washed with neutralizing buffer, and bound proteins were then eluted by addition of the corresponding elution buffer (for $\mathrm{S}$ beads: $10 \mathrm{mM}$ Tris, $0.5 \mathrm{M} \mathrm{NaCl}$, $\mathrm{pH} 10$; for Q beads: $10 \mathrm{mM} \mathrm{NaAc}, 0.5 \mathrm{M} \mathrm{NaCl}, \mathrm{pH}$ 4). After a 5-minute incubation at room temperature, beads were centrifuged ( $300 \mathrm{~g}, 5$ minutes) and supernatants collected and analyzed. Prior to chemotaxis analysis, the supernatants were diluted (1:100), and $\mathrm{pH}$ was adjusted to 7.0. Proteins were identified by peptide mass fingerprinting using MALDI-TOF mass spectrometry. The procedure was carried out by the Scottish Instrumentation and Resource Centre for Advanced Mass Spectrometry (SIRCAMS), School of Chemistry, University of Edinburgh. 
Immunoblotting. Conditioned media from viable and apoptotic BL2 and A549 cells were collected, and their protein content was TCA precipitated. Briefly, $100 \mu \mathrm{l}$ TCA was added in $1 \mathrm{ml}$ conditioned medium at $4^{\circ} \mathrm{C}$. Samples were centrifuged at $18,000 \mathrm{~g}$ and the pellets washed in ice-cold acetone before resuspension in sample buffer (NuPAGE; Invitrogen). Neutrophils $\left(5 \times 10^{6}\right.$ cells $\left./ \mathrm{ml}\right)$ were lysed for 15 minutes with $1 \%$ NP-40 in TBS containing protease inhibitor cocktail (Sigma Aldrich), aprotinin, leupeptin, pepstatin A, 4-(2-aminoethyl)benzenesulfonyl fluoride, sodium orthovanadate, benzamidine, levamisole, and $\beta$-glycerophosphate. Samples were centrifuged $\left(20,000 \mathrm{~g}, 4^{\circ} \mathrm{C}, 15\right.$ minutes $)$ and resolved by SDS-PAGE using 4\%-12\% Bis-Tris gels (NuPAGE; Invitrogen). Proteins were then electroblotted onto a nitrocellulose membrane (NuPAGE; Invitrogen), blocked with $0.5 \%$ (for lactoferrin) or 3\% BSA (for ERK), and probed with monoclonal mouse anti-human lactoferrin (1:100; LF.2B8; AbD Serotec) or mouse monoclonal anti-MAPK activated (diphosphorylated ERK1 and ERK2) antibody (1:1,000; Sigma-Aldrich) or polyclonal mouse ERK2 (1:1,000; Santa Cruz Biotechnology Inc.) or rabbit monoclonal anti-IкB $\alpha(74)$ (1:2,500; E130; Abcam) followed by HRP-conjugated goat anti-mouse IgG (1:2,000; Amersham) or HRP-conjugated goat anti-rabbit IgG (1:2,500; Dako) and visualized using ECL (GE Healthcare).

Binding studies. Biotinylation of human milk-derived lactoferrin was performed using EZ-Link Sulfo-NHS-LC-Biotin (Pierce, Thermo Scientific). Fresh neutrophils were exposed to biotinylated lactoferrin $(10 \mu \mathrm{g} / \mathrm{ml})$ at $37^{\circ} \mathrm{C}$ for 1 hour, after which the cells were washed and lysates prepared, resolved by SDS-PAGE, electroblotted, blocked with $0.1 \%$ PBS-Tween, and probed with HRP-conjugated streptavidin (Dako). For Scatchard analyses, ${ }^{125}$ I-labeled human milk-derived lactoferrin, prepared using Pierce Iodination Reagent (Thermo Scientific), was added at a constant amount to fresh human neutrophils in the presence of increasing amounts of cold, unlabeled lactoferrin. After 30 minutes at $4^{\circ} \mathrm{C}$, cells were washed 3 times before gamma counting.
Measurement of $\left[\mathrm{Ca}^{2+}\right]_{i}$. Measurement of $\left[\mathrm{Ca}^{2+}\right]_{\mathrm{i}}$ was performed as previously described (75). Briefly, freshly isolated neutrophils were resuspended $\left(10^{7} / \mathrm{ml}\right.$ ) in HBSS (without $\mathrm{Ca}^{2+} / \mathrm{Mg}^{2+}$ ) and were incubated with $2 \mu \mathrm{M}$ FURA 2/AM (Calbiochem) at $37^{\circ} \mathrm{C}$ for 30 minutes. The cells were washed twice, resuspended at $2 \times 10^{6} / \mathrm{ml}$ in HBSS (with $\mathrm{Ca}^{2+} / \mathrm{Mg}^{2+}$ ), incubated for an additional 30 minutes at $37^{\circ} \mathrm{C}$ in the presence of lactoferrin $(10 \mu \mathrm{g} / \mathrm{ml})$, and then stimulated with $\mathrm{PMLP}(1 \mathrm{nM}$ or $10 \mathrm{nM})$. [Ca $\left.{ }^{2+}\right]_{\mathrm{i}}$ levels were determined based on 340:380 $\mathrm{nm}$ dual wavelength excitation in a PerkinElmer luminescence spectrometer at $37^{\circ} \mathrm{C}$ with constant stirring. Calibration was performed after each experiment using Triton $\mathrm{X}\left(R_{\max }\right)$ and $\operatorname{EGTA}\left(R_{\min }\right)\left(R_{\max }\right.$ and $R_{\min }$ are the maximum and minimum 340:380 fluorescence ratios, respectively). $[\mathrm{Ca} 2+]_{\mathrm{i}}$ was calculated based on the $340: 380$ $\mathrm{nm}$ fluorescence ratio.

Statistics. Results from multiple experiments are presented as mean $\pm \mathrm{SEM}$. One-way ANOVA was performed, followed by Bonferroni's post-hoc test. In all cases, $P$ values of 0.05 or less were considered significant.

\section{Acknowledgments}

The authors thank Jason King for help in the lentiviral transduction of cells and the MRC and Leukaemia Research (United Kingdom) for supporting this work.

Received for publication May 16, 2008, and accepted in revised form October 15, 2008.

Address correspondence to: Christopher D. Gregory, MRC Centre for Inflammation Research, University of Edinburgh, Queen's Medical Research Institute, 47 Little France Crescent, Edinburgh EH16 4TJ, United Kingdom. Phone: 44-131-242-9170; Fax: 44131-242-9171; E-mail: chris.gregory@ed.ac.uk.
1. Lauber, K., et al. 2003. Apoptotic cells induce migration of phagocytes via caspase-3-mediated release of a lipid attraction signal. Cell. 113:717-730.

2. Truman, L.A., et al. 2008. $\mathrm{CX}_{3} \mathrm{CL} 1 /$ fractalkine is released from apoptotic lymphocytes to stimulate macrophage chemotaxis. Blood. 10.1182/blood2008-06-162404

3. Henson, P.M., and Hume, D.A. 2006. Apoptotic cell removal in development and tissue homeostasis. Trends Immunol. 27:244-250.

4. Ravichandran, K.S., and Lorenz, U. 2007. Engulfment of apoptotic cells: signals for a good meal. Nat. Rev. Immunol. 7:964-974.

5. Savill, J., Dransfield, I., Gregory, C., and Haslett, C. 2002. A blast from the past: clearance of apoptotic cells regulates immune responses. Nat. Rev. Immunol. 2:965-975.

6. Wyllie, A.H., Kerr, J.F., and Currie, A.R. 1980. Cell death: the significance of apoptosis. Int. Rev. Cytol. 68:251-306

7. Cohen, P.L., et al. 2002. Delayed apoptotic cell clearance and lupus-like autoimmunity in mice lacking the c-mer membrane tyrosine kinase. J. Exp. Med. 196:135-140.

8. Hanayama, R., et al. 2004. Autoimmune disease and impaired uptake of apoptotic cells in MFGE8-deficient mice. Science. 304:1147-1150.

9. Huynh, M.L., Fadok, V.A., and Henson, P.M. 2002. Phosphatidylserine-dependent ingestion of apoptotic cells promotes TGF- $\beta 1$ secretion and the resolution of inflammation. J. Clin. Invest. 109:41-50.

10. Fadok, V.A., Bratton, D.L., Frasch, S.C., Warner M.L., and Henson, P.M. 1998. The role of phosphatidylserine in recognition of apoptotic cells by phagocytes. Cell Death Differ. 5:551-562.

11. Voll, R.E., et al. 1997. Immunosuppressive effects of apoptotic cells. Nature. 390:350-351.

12. Truman, L.A., Ogden, C.A., Howie, S.E., and Grego- ry, C.D. 2004. Macrophage chemotaxis to apoptotic Burkitt's lymphoma cells in vitro: role of CD14 and CD36. Immunobiology. 209:21-30.

13. Huttenlocher, A., Sandborg, R.R., and Horwitz, A.F. 1995. Adhesion in cell migration. Curr. Opin. Cell Biol. 7:697-706.

14. Iijima, M., and Devreotes, P. 2002. Tumor suppressor PTEN mediates sensing of chemoattractant gradients. Cell. 109:599-610.

15. Parent, C.A., and Devreotes, P.N. 1999. A cell's sense of direction. Science. 284:765-770.

16. Servant, G., et al. 2000. Polarization of chemoattractant receptor signaling during neutrophil chemotaxis. Science. 287:1037-1040.

17. Drubin, D.G., and Nelson, W.J. 1996. Origins of cell polarity. Cell. 84:335-344.

18. Hogg, N., and Leitinger, B. 2001. Shape and shift changes related to the function of leukocyte integrins LFA-1 and Mac-1. J. Leukoc. Biol. 69:893-898.

19. Weiss, S.J. 1989. Tissue destruction by neutrophils. N. Engl. J. Med. 320:365-376.

20. Serhan, C.N., and Savill, J. 2005. Resolution of inflammation: the beginning programs the end. Nat. Immunol. 6:1191-1197.

21. Takata, S., et al. 1994. Remodeling of neutrophil phospholipids with $15(\mathrm{~S})$-hydroxyeicosatetraenoic acid inhibits leukotriene B4-induced neutrophil migration across endothelium. J. Clin. Invest. 93:499-508.

22. Haslett, C. 1992. Resolution of acute inflammation and the role of apoptosis in the tissue fate of granulocytes. Clin. Sci. (Lond.). 83:639-648.

23. Serhan, C.N. 2005. Novel omega-3-derived local mediators in anti-inflammation and resolution. Pharmacol. Ther. 105:7-21.

24. Rossi, A.G., et al. 2006. Cyclin-dependent kinase inhibitors enhance the resolution of inflammation by promoting inflammatory cell apoptosis.
Nat. Med. 12:1056-1064

25. Schwab, J.M., Chiang, N., Arita, M., and Serhan, C.N. 2007. Resolvin E1 and protectin D1 activate inflammation-resolution programmes. Nature. 447:869-874

26. Maneva, A.I., Sirakov, L.M., and Manev, V.V. 1983. Lactoferrin binding to neutrophilic polymorphonuclear leucocytes. Int. J. Biochem. 15:981-984.

27. Spik, G., et al. 1994. Characterization of two kinds of lactotransferrin (lactoferrin) receptors on different target cells. Adv. Exp. Med. Biol. 357:13-19.

28. Zucali, J.R., Broxmeyer, H.E., Levy, D., and Morse, C. 1989. Lactoferrin decreases monocyte-induced fibroblast production of myeloid colony-stimulating activity by suppressing monocyte release of interleukin-1. Blood. 74:1531-1536.

29. Broxmeyer, H.E., Smithyman, A., Eger, R.R., Meyers, P.A., and de Sousa, M. 1978. Identification of lactoferrin as the granulocyte-derived inhibitor of colony-stimulating activity production. J. Exp. Med. 148:1052-1067.

30. Broxmeyer, H.E., et al. 1986. The effects in vivo of purified preparations of murine macrophage colony stimulating factor- 1 , recombinant murine granulocyte-macrophage colony stimulating factor and natural and recombinant murine interleukin 3 without and with pretreatment of mice with purified iron-saturated human lactoferrin. Immunobiology. 172:168-174.

31. Pozzan, T., Lew, D.P., Wollheim, C.B., and Tsien, R.Y. 1983. Is cytosolic ionized calcium regulating neutrophil activation? Science. 221:1413-1415.

32. Lew, P.D., Dayer, J.M., Wollheim, C.B., and Pozzan, T. 1984. Effect of leukotriene B4, prostaglandin E2 and arachidonic acid on cytosolic-free calcium in human neutrophils. FEBS Lett. 166:44-48.

33. Nigam, S., Muller, S., and Walzog, B. 1992. Effect of staurosporine on $\mathrm{fMet}-\mathrm{Leu}-\mathrm{Phe}$-stimulated human 
neutrophils: dissociated release of inositol 1, 4, 5trisphosphate, diacylglycerol and intracellular calcium. Biochim. Biophys. Acta. 1135:301-308.

34. Szczur, K., Xu, H., Atkinson, S., Zheng, Y., and Filippi, M.D. 2006. Rho GTPase CDC42 regulates directionality and random movement via distinct MAPK pathways in neutrophils. Blood. 108:4205-4213.

35. Siebert, P.D., and Huang, B.C. 1997. Identification of an alternative form of human lactoferrin mRNA that is expressed differentially in normal and tumor-derived cell lines. Proc. Natl. Acad. Sci. U. S. A. 94:2198-2203.

36. Legrand, D., Elass, E., Carpentier, M., and Mazurier, J. 2005. Lactoferrin: a modulator of immune and inflammatory responses. Cell. Mol. Life Sci. 62:2549-2559.

37. Ward, P.P., Paz, E., and Conneely, O.M. 2005. Multifunctional roles of lactoferrin: a critical overview. Cell. Mol. Life Sci. 62:2540-2548.

38. Crouch, S.P., Slater, K.J., and Fletcher, J. 1992. Regulation of cytokine release from mononuclear cells by the iron-binding protein lactoferrin. Blood. 80:235-240.

39. Haversen, L., et al. 2002. Lactoferrin down-regulates the LPS-induced cytokine production in monocytic cells via NF-kappa B. Cell Immunol. 220:83-95.

40. Togawa, J., et al. 2002. Oral administration of lactoferrin reduces colitis in rats via modulation of the immune system and correction of cytokine imbalance. J. Gastroenterol. Hepatol. 17:1291-1298.

41. Zimecki, M., Artym, J., Chodaczek, G., Kocieba, M. and Kruzel, M. 2005. Effects of lactoferrin on the immune response modified by the immobilization stress. Pharmacol. Rep. 57:811-817.

42. Legrand, D., Elass, E., Carpentier, M., and Mazurier, J. 2006. Interactions of lactoferrin with cells involved in immune function. Biochem. Cell Biol. 84:282-290.

43. Anderson, R., Steel, H.C., and Tintinger, G.R 2005. Inositol 1, 4, 5-triphosphate-mediated shuttling between intracellular stores and the cytosol contributes to the sustained elevation in cytosolic calcium in FMLP-activated human neutrophils. Biochem. Pharmacol. 69:1567-1575.

44. Takenawa, T., Homma, Y., and Nagai, Y. 1983. Role of $\mathrm{Ca} 2+$ in phosphatidylinositol response and arachidonic acid release in formylated tripeptideor Ca2+ ionophore A23187-stimulated guinea pig neutrophils. J. Immunol. 130:2849-2855.

45. O'Flaherty, J.T., Rossi, A.G., Jacobson, D.P., and Redman, J.F. 1991. Roles of Ca2+ in human neutrophil responses to receptor agonists. Biochem. J. 277:705-711.

46. Thompson, H.L., Shiroo, M., and Saklatvala, J. 1993. The chemotactic factor $\mathrm{N}$-formylmethionylleucyl-phenylalanine activates microtubule-associated protein 2 (MAP) kinase and a MAP kinase kinase in polymorphonuclear leucocytes. Biochem. J. 290:483-488.
47. Thompson, H.L., Marshall, C.J., and Saklatvala, J. 1994. Characterization of two different forms of mitogen-activated protein kinase kinase induced in polymorphonuclear leukocytes following stimulation by $\mathrm{N}$-formylmethionyl-leucyl-phenylalanine or granulocyte-macrophage colony-stimulating factor. J. Biol. Chem. 269:9486-9492.

48. Van Lint, J., Van Damme, J., Billiau, A., Merlevede, W., and Vandenheede, J.R. 1993. Interleukin-8 activates microtubule-associated protein 2 kinase (ERK1) in human neutrophils. Mol. Cell. Biochem. 127-128:171-177.

49. de Lillo, A., Tejerina, J.M., and Fierro, J.F. 1992. Interaction of calmodulin with lactoferrin. FEBS Lett. 298:195-198.

50. Verploegen, S., et al. 2002. Role of Ca2+/calmodulin regulated signaling pathways in chemoattractant induced neutrophil effector functions. Comparison with the role of phosphotidylinositol-3 kinase. Eur. J. Biochem. 269:4625-4634.

51. Lian, J.P., et al. 2001. Antagonists of calcium fluxes and calmodulin block activation of the p21-activated protein kinases in neutrophils. J. Immunol. 166:2643-2650.

52. Downey, G.P., et al. 1996. Chemotactic peptideinduced activation of MEK-2, the predominant isoform in human neutrophils. Inhibition by wortmannin. J. Biol. Chem. 271:21005-21011.

53. Naccache, P.H., et al. 1980. Calmodulin inhibitors block neutrophil degranulation at a step distal from the mobilization of calcium. Biochem. Biophys. Res. Commun. 97:62-68.

54. Birgens, H.S., Hansen, N.E., Karle, H., and Kristensen, L.O. 1983. Receptor binding of lactoferrin by human monocytes. Br. J. Haematol. 54:383-391.

55. Van Snick, J.L., and Masson, P.L. 1976. The binding of human lactoferrin to mouse peritoneal cells. J. Exp. Med. 144:1568-1580.

56. de la Rosa, G., Yang, D., Tewary, P., Varadhachary, A., and Oppenheim, J.J. 2008. Lactoferrin acts as an alarmin to promote the recruitment and activation of APCs and antigen-specific immune responses. J. Immunol. 180:6868-6876.

57. Elass, E., Masson, M., Mazurier, J., and Legrand, D. 2002. Lactoferrin inhibits the lipopolysaccharide-induced expression and proteoglycan-binding ability of interleukin-8 in human endothelial cells. Infect. Immun. 70:1860-1866.

58. Hayhoe, R.P., et al. 2006. Annexin 1 and its bioactive peptide inhibit neutrophil-endothelium interactions under flow: indication of distinct receptor involvement. Blood. 107:2123-2130.

59. Ly, N.P., et al. 2005. Netrin-1 inhibits leukocyte migration in vitro and in vivo. Proc. Natl. Acad. Sci. U. S. A. 102:14729-14734.

60. Cornish, J., et al. 2004. Lactoferrin is a potent regulator of bone cell activity and increases bone formation in vivo. Endocrinology. 145:4366-4374.

61. Ishii, T., et al. 2007. Bovine lactoferrin stimulates anchorage-independent cell growth via membrane-associated chondroitin sulfate and heparan sulfate proteoglycans in PC12 cells. J. Pharmacol. Sci. 104:366-373.

62. Golpon, H.A., et al. 2004. Life after corpse engulfment: phagocytosis of apoptotic cells leads to VEGF secretion and cell growth. FASEB J. 18:1716-1718.

63. Morimoto, K., et al. 2001. Alveolar macrophages that phagocytose apoptotic neutrophils produce hepatocyte growth factor during bacterial pneumonia in mice. Am. J. Respir. Cell Mol. Biol. 24:608-615.

64. Gorria, M., et al. 2008. A new lactoferrin- and irondependent lysosomal death pathway is induced by benzo[a]pyrene in hepatic epithelial cells. Toxicol. Appl. Pharmacol. 228:212-224.

65. Katunuma, N., et al. 2006. A novel apoptosis cascade mediated by lysosomal lactoferrin and its participation in hepatocyte apoptosis induced by D-galactosamine. FEBS Lett. 580:3699-3705.

66. Damiens, E., et al. 1999. Lactoferrin inhibits G1 cyclin-dependent kinases during growth arrest of human breast carcinoma cells. J. Cell. Biochem. 74:486-498.

67. Xiao, Y., Monitto, C.L., Minhas, K.M., and Sidransky, D. 2004. Lactoferrin down-regulates G1 cyclindependent kinases during growth arrest of head and neck cancer cells. Clin. Cancer Res. 10:8683-8686.

68. Lozupone, F., et al. 2000. Murine granulocytes control human tumor growth in SCID mice. Int. J. Cancer. 87:569-573.

69. Di Carlo, E., et al. 2001. The intriguing role of polymorphonuclear neutrophils in antitumor reactions. Blood. 97:339-345.

70. Grote, D., Cattaneo, R., and Fielding, A.K. 2003. Neutrophils contribute to the measles virusinduced antitumor effect: enhancement by granulocyte macrophage colony-stimulating factor expression. Cancer Res. 63:6463-6468.

71. Dallegri, F., et al. 1991. Tumor cell lysis by activated human neutrophils: analysis of neutrophil-delivered oxidative attack and role of leukocyte function-associated antigen 1. Inflammation. 15:15-30.

72. Hoffer, P.B., Miller-Catchpole, R., and Turner, D.A. 1979. Demonstration of lactoferrin in tumor tissue from two patients with positive gallium scans. J. Nucl. Med. 20:424-427.

73. Dransfield, I, Stocks, S.C, and Haslett, C. 1995. Regulation of cell adhesion molecule expression and function associated with neutrophil apoptosis. Blood. 85:3264-3273.

74. Bournazos, S., Rennie, J., Hart, S.P., Fox, K.A., and Dransfield, I. 2008. Monocyte functional responsiveness after PSGL-1-mediated platelet adhesion is dependent on platelet activation status. Arterioscler. Thromb. Vasc. Biol. 28:1491-1498.

75. McMeekin, S.R., Dransfield, I., Rossi, A.G., Haslett, C., and Walker, T.R. 2006. E-selectin permits communication between PAF receptors and TRPC channels in human neutrophils. Blood. 107:4938-4945. 